\title{
EARLY CHILDHOOD EDUCATORS' KNOWLEDGE AND PERCEPTION OF MENTAL HEALTH IN THEIR PRESCHOOL CLASSROOM
}

by

\author{
Asia Leon \\ Bachelor of Child Development, Seneca College, 2018
}

\author{
A Major Research Paper \\ Presented to Ryerson University \\ in partial fulfillment of the \\ requirements for the degree of \\ Master of Arts \\ in the Program of \\ Early Childhood Studies
}

Toronto, Ontario, Canada, 2020

(C) Asia Leon 2020 


\section{AUTHOR'S DECLARATION FOR ELECTRONIC SUBMISSION OF A MRP}

I hereby declare that I am the sole author of this MRP. This is a true copy of the MRP, including any required final revisions.

I authorize Ryerson University to lend this MRP to other institutions or individuals for the purpose of scholarly research

I further authorize Ryerson University to reproduce this MRP by photocopying or by other means, in total or in part, at the request of other institutions or individuals for the purpose of scholarly research.

I understand that my MRP may be made electronically available to the public. 


\title{
ABSTRACT \\ EARLY CHILDHOOD EDUCATORS' KNOWLEDGE AND PERCEPTION OF MENTAL HEALTH IN THEIR PRESCHOOL CLASSROOM
}

\author{
Master of Arts, 2020 \\ Asia Leon \\ Program of Early Childhood Studies, \\ Ryerson University
}

Decades of research on the impact of early mental health challenges in young children suggest that the effects are detrimental on children's development without the presence of protective factors. As a factor for promoting mental health, early childhood classrooms and educators create optimal opportunities to identify and respond to children's mental health concerns. However, little research explores the knowledge and skills of ECEs to effectively promote and support mental health challenges. The present study aimed to identify the mental health promotional knowledge, practices and experiences of ECEs in their preschool classrooms, as well as contribute to mental health promotion. Findings indicate that ECEs have little knowledge in promoting and supporting mental health in their classrooms and how that influences their practice. Suggestions for policymakers, early childhood practitioners, and future research are provided. 


\section{ACKNOWLEDGEMENTS}

First and foremost, thank you to my graduate supervisor, Dr. David Day, for your guidance and willingness to take me under your academic wing. Your critical feedback, support and knowledge provided me with much learning. To my second reader, Dr. Kathrine Underwood, thank you for your willingness to examine my work. I am beyond thankful. I would also like to thank Dr. Jennifer Sullivan, my undergraduate thesis supervisor, for being a part of my editorial process. Your insight has been invaluable.

I would like to thank all my friends and family for believing in me. Your support and encouragement allowed me to be where I am today. I am also beyond thankful for my second family (Natalia and Daniel), who allowed me to take over their dining room table as my personal workspace with notes, markers, chargers, food, drinks, you name it! I could not have completed my MRP without your generosity.

To my sister Kizzie, you've been a rock. Thank you for continuously supporting and lifting me up. You have been there every step of the way. I cannot be prouder to call you my sister.

To my love Ezequiel, you came along just when I needed you. I am eternally grateful for you by my side, pushing me to go above and beyond. Thank you for being my knight, my peace, my best friend.

I love you all. 


\section{DEDICATION}

I would like to dedicate this research paper to my daughter, Taliyah. You are the biggest motivator of all. I want you to know that even when life seems too challenging, keep pushing through. I am extremely blessed that I've been given the opportunity to be your mother. Thank you for giving meaning to everything I do. 


\section{TABLE OF CONTENTS}

Author's Declaration

ii

Abstract

Acknowledgements

iv

Dedication

Table of Contents

vi

Tables

Figures

ix

Appendices

Chapter 1: Introduction

1.1 Purpose of the Study 3

1.2 Key Terms Definition 5

$\begin{array}{ll}\text { 1.3 Conceptual and Theoretical Framework } & 7\end{array}$

Chapter 2: Literature Review 9

$\begin{array}{ll}2.1 \text { Overview } & 9\end{array}$

2.2 Concerns for Early Childhood Educators 9

2.3 Social emotional development and behaviour 11

2.4 Role of the Educator 13

$\begin{array}{ll}2.5 \text { Need for professional development } & 15\end{array}$

2.6 School Readiness 16

$\begin{array}{ll}\text { 2.7 Conclusion } & 18\end{array}$

$\begin{array}{ll}\text { Chapter 3: Methods } & 19\end{array}$

$\begin{array}{ll}3.1 \text { Overview } & 19\end{array}$

$\begin{array}{ll}\text { 3.2 Participants } & 19\end{array}$

$\begin{array}{ll}\text { 3.3 Procedure } & 21\end{array}$ 
$\begin{array}{ll}\text { Chapter 4: Findings } & 25\end{array}$

$\begin{array}{ll}\text { 4.1 Overview } & 25\end{array}$

4.2 Research Question One: Supporting and promoting infant mental health in their $\begin{array}{ll}\text { classroom } & 25\end{array}$

4.3 Research Question Two: Strategies and Resources 30

4.4 Research Question Three: Concept of mental health 32

4.5 Research Question Four: Further Support Needed 39

Chapter 5: Discussion 42

$\begin{array}{ll}5.1 \text { Overview } & 42\end{array}$

5.2 Mental Health Promotion Knowledge 42

5.3 Mental Health Promotion Practices $\quad 48$

5.4 Limitations

5.5 Implications

5.6 Future Research 55

5.7 Conclusions $\quad 56$

$\begin{array}{ll}\text { Reference List } & 69\end{array}$ 


\section{LIST OF TABLES}

Table 1: List of Internalizing and Externalizing Behaviours (Kulkarni et al., 2019)

$\begin{array}{ll}\text { Table 2: Demographic Information } & 20\end{array}$

Table 3: Semi- Structure Interview Question Guide 26

Table 4: Responses expanding on confidence level 28

Table 5: Behaviour Type and frequency of behaviours reported 33

Table 6: Descriptors of Mental Health Disorders 35

Table 7: Social-emotional Well-being Criterion (Squires \& Bricker (2009) 37

Table 8: Criterion Scores of Social-emotional Well-being 39 


\section{LIST OF FIGURES}

Figure 1: Age range of participants. 


\section{LIST OF APPENDICES}

Appendix A - Recruitment Flyer

Page 57

Appendix B - Consent Agreement

Page 58

Appendix C - Facebook Post and Email

Page 63

Appendix D - Supervisor Email

Page 64

Appendix E - Scenario

Page 66

Appendix F - Interview Question Guide

Page 67 


\section{CHAPTER 1. INTRODUCTION}

Human development generally progresses in a manner that is predictable, organized, and hierarchical. From conception, the foundation for development occurs early in life and sets the course for determinants of later health (Cho, 2019). Advances in epigenetics and neuroscience highlight what we know about the influence of the environment during sensitive periods of development (Britto \& Pérez-Escamilla, 2013). These sensitive periods tell us that there is a window of opportunity in childhood for language, cognitive, social and emotional development (Cho, 2019; Britto \& Pérez-Escamilla, 2013). As development is activated by environmental stimulation, early experiences are crucial in shaping the development and capacity of the brain (Cho, 2019). Unfortunately, when children are exposed to early adversity during these sensitive periods, without the presence of a protective factor (Kulkarni, Khambati, Sundar, Kelly, Summers, \& Short, 2019) it can negatively influence their trajectory and thus their mental health.

Science shows that early positive experiences build the foundation for good mental health (Kulkarni et al., 2019). Positive mental health in children is a pathway for future development, guiding the formation of relationships and the ability to cope with everyday stressors (Centre on the Developing Child, 2012). There is evidence that shows, "significant mental health problems can and do occur in young children" (Centre on the Developing Child, 2013, para. 2). Children who experience prolonged adversity are more susceptible to mental health challenges. Further, the promotion of mental health and early intervention methods in young children as they grow up, leads to a strong economy and society (Heckman, 2011).

Mental health promotion is the preventative effort that is taken even when there are no signs of a mental health problem. While there is evidence of the risk of mental health challenges in the face of adversity, it is also evident that, "secure, nurturing and responsive care in the early 
years of life provides protection from environmental risks" (Sims, Davis, Davies, Nicholson, Harrison, Herman, Waters, Marshall, Cook \& Priest, 2012, p. 139). Childcare environments can provide opportunities for children to socialize and develop relationships (Landy, 2009).

However, in these settings, behaviour and social-emotional problems may emerge if children are unable to manage structured times and transitions (Aviles, Anderson, \& Davila, 2006). Early childhood environments can play a crucial role in supporting and promoting children's mental health. This means that early childhood educators (ECEs) may be key factors in creating environments that promote early mental health. Further, ECEs need to also have some capacity to provide support when children are at risk for mental illnesses. Opportunities that enhance capacity building are crucial for ECEs to be able to appropriately address children's mental health concerns. It is important that ECEs are able to recognize behaviour changes (Khodarahmi, 2019) and are competent in recognizing the early signs of mental health issues as they spend a great amount of time with children. Furthermore, in early childhood, behaviour and emotional challenges may contribute to children's mental health problems (Giannakopoulos et al., 2014).

Poulou (2015) states that, "the preschool period can be seen as an optimal time to identify and reduce early signs of problems, before they develop into permanent patterns" (p. 233). The preschool period is an essential time for children to develop the skills to equip them for success in school (Kulkarni et al., 2019). School readiness is not just about academic readiness, but is also about children's ability to follow instructions, concentrate, communicate effectively and manage their emotions. Moreover, when children are identified as having a mental health challenge earlier, there is a window of opportunity for intervention due to the neuroplasticity in early childhood (Poulou, 2015; Dougherty et al., 2015). Thus, since preschool children spend a significant amount of time with their ECEs, how significant preschool is for school readiness, 
and how children's early experiences are essential for the foundation of mental health, it is clear that ECEs need to be knowledgeable in mental health promotion and prevention strategies.

\subsection{Purpose of the Study}

The purpose of the current study is to explore early childhood educator's knowledge and experiences about infant mental health and the signs of early mental health problems. The educator's beliefs and practices were explored using interviews to capture a range of perspectives of ECEs towards young children. The current study is aimed at building a knowledge of (1) how early childhood educators are supporting and promoting infant mental health in their classroom, (2) the strategies and resources ECEs are using in their classroom to promote mental health, (3) what ECEs consider as a mental health challenge, (4) and what ECEs need to further support mental health in their classrooms.

\section{Canadian Statistics}

In Canada, between $10 \%$ to $20 \%$ of children may develop a mental health disorder (Canadian Institute for Health Information, 2020; World Health Organization, 2020). In Ontario, "approximately $20 \%$ of children have a mental health disorder, which causes significant distress and impairs their functions at home, school, with peers, and in the community" (Lee, 2012, p. 7). Globally, mental health disorders account for $13 \%$ of the burden of disease for all ages (Canadian Institute for Health Information, 2020). Research indicates that mental health problems are on the rise as more children are exhibiting mental health problems in the early years (Bricker, Schoen, Davis, \& Squires, 2004; Lee, 2012; Penney, Young, Butler, Maich, \& Philpott, 2019). According to von Klitzing, Dohnert, and Grube (2015), “about 17\% of all children suffer from a mental disorder in early childhood, defined as the period up to the age of 6 
years" (p. 1). Some challenges to mental health include depression, anxiety, and behavioural and emotional difficulties (Lee, 2012). Additionally, specific types of disorders in early childhood range from relationship disorders, food intake disorders, motor regulation disorders, and affect disorders (von Klitzing et al., 2015). Mental health disorders are quite common in early childhood; the most common mental health disorders in early childhood are depression, anxiety and attention deficit hyperactivity disorder (Dryden-Edwards, 2018).

Moreover, the percentage of children having more than one disorder simultaneously is 40-50\% (Lee, 2012). Mental health problems occur as early as infanthood. Prevalence rates and statistics were easy to find specifically for mental health disorders in childhood. However, the prevalence rates of mental health issues in children under the age of 6 were difficult to find. Further, according to von Klitzing et al. (2015), these prevalence rates are even more challenging to determine from the Canadian context. Nonetheless, research urges us to critically understand the seriousness of mental health problems in early childhood (Lee, 2012).

\section{College of Early Childhood Educators - The Role of Continuous Professional Learning}

Educators in the province of Ontario are required to engage in a number of professional development opportunities that intended to enhance capacity building and improve their skills and practice. The College of Early Childhood Educators (CECE) of Ontario developed a Continuous Professional Learning (CPL) program that allows educators to engage in ongoing professional learning. According to the CECE (2020), "The CPL program is a framework and formal process to help RECEs increase their knowledge and skills and ensure quality professional practice throughout their careers" (p.1). The program requires all members who are registered to complete the annual CPL training. Requirements follow a sequential order every two years: Year One is a self-assessment tool, and a professional learning plan, then engagement 
in activities pertaining to the plan, tracking and documenting learning, and finally a self-report stating that they have completed the requirements of the CPL program (CECE, 2020). Year two asks members to review and update their plan, continue to engage in activities pertaining to the plan, as well as tracking and documenting their learning, and finally reflect on and self-report completion. Therefore, this means that educators can choose preferred content to engage in as their professional learning.

Further, to ensure that members are complying with the requirements, in September 2019 the CECE implemented an auditing process. The CECE (2020) stated, "Reviewing CPL program records allows the College to evaluate members' understanding of the CPL program components and determine what additional resources may be needed to enhance member engagements in the CPL program and compliance with requirements" (p.3). Failure to do so can result in suspension of member's certification.

\subsection{Definition of Terms}

Infant mental health. The Infant Mental Health Promotion organization is a not-forprofit education and training organisation that focuses on early childhood mental health and infant mental health (Kulkarni et al., 2019). The term infant mental health describes young children's (ages 0-5) developing capacity to foster secure bonding relationships with adults and peers, to understand and express a variety of emotions, and to explore their learning environment alongside the diverse relationship among family, community and culture (Cohen, Oser, \& Quigley, 2012).

Early childhood educators (ECEs). For the purpose of this study, ECEs are individuals who are registered with the College of ECEs (CECE) in Ontario. ECEs in this study can hold a 
diploma and/or Bachelor's degree in early childhood education. Early childhood educator's working in a preschool classroom are the target population for this study.

Preschool classroom. Preschool classrooms are classrooms that have a designated ECE within a licensed childcare centre in the Greater Toronto Area (GTA). Children in this age group vary from ages 3-5 years old.

Diagnostic criteria for mental illness. For the purpose of this study, anxiety disorder, depressive disorder, and attention deficit hyperactivity disorder are defined by the diagnostic criteria in the Diagnostic Classification of Mental Health and Developmental Disorders of Infancy and Early Childhood (DC: 0-5).

Anxiety disorder (generalized anxiety disorder). The criteria for a diagnosis of anxiety disorder in children is the "young child experiences marked and persistent anxiety or worry more days than not. Worries may include anxiety about future events, the appropriateness of past behavior, and concerned about competence and one or more areas. The young child is unable to regulate the anxiety or worry (e.g., the young child me repeatedly asked the parents for reassurance). The anxiety and worry occur during two or more activities or settings or within two or more relationships" (Zero to Three, 2005, p. 50).

Depressive Disorder. Criteria for a diagnosis of depressive disorder in children is “depressed mood or irritability across activities, more days than not for at least two weeks, as indicated by either the child's direct expression, (e.g., "I'm sad") or observations made by others (e.g., the young child appears sad or is tearful, affect is flat, or the young child has frequent tantrums). Markedly diminished pleasure or interest at all, or almost all, activities, such as imitation of play and interaction with caregivers - across activities. Significant change in appetite, insomnia or hypersomnia, fatigue or loss of energy" (Zero to Three, 2005, p. 66). 
Attention Deficit Hyperactivity Disorder (ADHD). ADHD is defined as "a disorder of developmentally inappropriate levels of inattention or hyperactivity - impulsivity that interfere with the functioning of a young child and their family (Zero to Three, 2005, p. 25).

\subsection{Conceptual and Theoretical Framework}

Mental health is something that everyone has the capacity for. The World Health Organization (WHO) (2014) identifies mental health as more than the absence of mental illness. According to the WHO, mental health is defined as:

...A state of well-being in which every individual realizes his or her own potential, can cope with the normal stresses of life, can work productively and fruitfully, and is able to make a contribution to her or his community (World Health Organization, 2014, pg. 1).

Positive mental health should be prioritized with efforts that include prevention strategies and intervention to promote holistic health outcomes. Effective prevention and intervention practices and services should be based on individualized needs that take into account aspects of ethnicity, culture, age, sex, race, etc. As an educator in the field of early childhood studies, my personal beliefs are that educators should be knowledgeable in: (1) promoting mental health in their classrooms, (2) recognizing the early signs of mental health challenges, and (3) responding appropriately to the needs of children who are exhibiting these signs, which includes implementing strategies, resources and programs (Farrel \& Travers, 2005; Sims et al., 2012; Isaksson et al., 2017).

The theoretical framework that frames this study uses tenets of Bandura's self-efficacy model. Bandura defines self-efficacy as an individual's beliefs about their ability to successfully complete a task (Ackerman, 2020). An educator's ability to respond appropriately to the needs of children relies on how much they know and how they approach the challenge/opportunity. 
Mastery experience is the most effective way to build self-efficacy (Tugsbaatar, 2020).

According to Shelton (2013), the literature shows that educators who have prepared for the field, including field experiences, can influence mastery experience. If educators have low selfefficacy, their classroom would reflect poorer performance levels. In contrast, educators who had experiences with responding appropriately to children's challenging behaviours would interpret their behaviours positively, thus having high self-efficacy levels. 


\section{CHAPTER 2}

\section{LITERATURE REVIEW}

\subsection{Overview}

The development of social-emotional skills in children is critical for their academic success, social relationships, and their behaviour. When children are exposed to early adversity, they are at risk for socio-emotional and behavioural problems. These childhood experiences are linked to lifelong negative impacts on children's health and wellbeing (Gartland et al., 2019; Hoffman, 2016). In order to understand children's mental health needs, we need to unpack what the adults in the lives of these children know about supporting and promoting their mental health.

This chapter is a synthesis of the literature chosen to provide context for the current study. Themes that will be discussed are as followed: concerns for early childhood educators, social emotional development and behaviour, the role of the educator, the need for professional development, and preschool mental health as the antecedent to readiness for school.

\subsection{Concerns for Early Childhood Educator}

Children's social-emotional difficulties can be a great concern for ECEs (Poulou, 2015). When children's behaviours are frustrating, educators must “expend additional effort to maintain positive supportive relationships" (Zinsser, Christensen, \& Torres, 2016, p. 58). Maintaining children's challenging behaviours can be a concern for ECEs.

Research investigating educator's emotional health and stress shows that teachers face many challenges within the classroom (Denham et al., 2017; Zinsser et al., 2016). The teaching profession is one that is considered stressful (Denham et al., 2017; Zinsser et al., 2016; Harmsen, Helms-Lorenz, Maulana, \& Veen, 2018). Research investigating stress in educators consistently find that educators are reporting significantly heavier workload than other professionals 
(Harmsen et al., 2018). As they are often exposed to emotional challenges exhibited by children, these can cause stressful experiences for the educators. Educator's emotional well-being can influence the way they teach and interact with children. When they are emotionally overwhelmed, they may lack the ability to the manage the classroom and exhibit appropriate emotional responses (Denham et al., 2017; Zinsser et al., 2016).

In contrast, Zinsser et al. (2016) states that, "during emotionally challenging times in the classroom, more competent teachers can potentially manage their physiological arousal in healthy ways that do not detract from their relationships with students and coworkers, enabling them to view their work as more enjoyable" (p. 57). It can be assumed that when ECEs are stressed with their work, there are poorer outcomes within the classroom, (i.e. poorer relationships with children, families and coworkers). Additionally, since ECEs' stress can be linked to poorer relationships with children, it can also be assumed that children exhibit negative behaviours in the classroom when ECEs are stressed (Denham et al., 2017; Zinsser et al., 2016). Stress in educators is concerning because of the effects on children's behaviour and learning. A study investigating stress and its effect on teachers found that there is a link between teacher's negative emotions and their teaching behaviours (Harmsen et al., 2018).

Educators and children are co-constructors in the socio-emotional climate of the classroom (Deham et al., 2017). Educators should model appropriate behaviour and emotion regulation for children to follow in the classroom. Childcare centres that invest in socialemotional development ensure that educators are equipped with supports to not only manage children mental health, but to manage their own mental health as well. Specifically, "when centers that offer more social-emotional supports (mental health consultants, social-emotional learning (SEL) curriculum, and classroom resources), teachers feel less depressed, are more 
satisfied with their jobs, report perceiving their centers' climate as more positive, and feel more supported in handling challenging student behaviors" (Zinsser et al., 2016, p. 63). The research supports the claim that educators teaching practices are dependent on their own social-emotional well-being.

\subsection{Social emotional development and behaviour}

According to the National Centre for Learning Disabilities (2020), "some children exhibit behaviors that fall outside of the normal, or expected, range of development. These behaviors emerge in a way or at a pace that is different from their peers" (para. 7). The behaviours of children who are on track with their development in the social-emotional domain allows them to regulate emotions and bear stressful situations, develop meaningful relationships with their peers and adults, and to learn from and explore their environments (Cohen et al., 2012). Additionally, positive social-emotional skills also allow children to participate in prosocial behaviours that include abilities like following instructions and following rules (Cohen et al., 2012). However, the relationship between genes and contextual factors may produce vulnerabilities in the socialemotional domain or the early onset of mental health problems (Cohen et al., 2012; Groh, Roisman, van IJzendoorn, Bakermans-Kranenburg, \& Fearon, 2012; Kulkarni et al., 2019). According to Kulkarni et al. (2019), behaviours and emotions that are observable can be a clear indicator of mental health concerns. In their literature review, the authors listed some behaviours that are commonly observed in young children, and shared a longer list of internalizing and externalizing behaviours (see Table 1):

Such observable behaviours and emotions may include (but are not 
limited to) aggressive, inattentive, impulsive or overactive behaviours (i.e. externalizing behaviours). Some children may also exhibit internalizing behaviours such as anxiety, social withdrawal, low energy and irritability (Kulkarni et al., 2019 p. \#13).

Additionally, internalizing behaviours often go unnoticed due to the subtleness and typical behaviours observed in early childhood (Cohen et al., 2005; Kulkarni et al., 2019). Gellner from the Health University of Utah states that "many behaviors that are seen as symptoms in mental disorders, such as shyness, anxiety, strange eating habits and temper tantrums, can occur as a normal part of a child's development" (Gellner, 2015, par. 6). Gellner continues to say that behaviours transcribe into symptoms when they last a long time and occur often, especially at an unusual age. Moreover, Landy (2009) states that four factors should be considered when identifying social-emotional concerns: severity, frequency, intensity and duration of the internalizing and/or externalizing behaviour (as cited in Kulkarni et al., 2019). Thus, it may be difficult for ECEs to differentiate between normative childhood behaviours and mental health concerns.

\section{Table 1}

List of Internalizing and Externalizing Behaviours (Kulkarni et al., 2019)

Internalizing Behaviors

Anxiousness

Perfectionism

Sadness

Fatigue or low energy

Social withdrawal

Irritability
Externalizing Behaviors

Inattention

Hyperactivity

Impulsivity

Aggression

Emotional fluctuations

Low frustration tolerance

Oppositional behavior 
ECEs and practitioners who do not have adequate knowledge in infant mental health may miss the early signs of children's mental health concern (Cohen et al., 2005; Kulkarni et al., 2019). Kulkarni et al.'s 2019 survey findings highlighted that early learning practitioners needed more knowledge in distinguishing between behaviours that are developmentally appropriate for a preschool child from those who are not. The evidence in the literature suggests that ECEs are a key factor in supporting and promoting children's mental health and without substantial knowledge and skills in that area, it leaves opportunity for children to be missed.

\subsection{Role of the Educator}

Educators in childcare can promote social-emotional development. They can play a key role in children's mental health and well-being due to their spending varying amount of time with children (as cited in Fazari, 2015). The Ministry of Education's 2013 report entitled "Supporting Mind" highlights that the events and duration of events occurring daily influences children's well-being, and that the education system is crucial in supporting the mental health of children. The role of the educator is not to diagnose but to support the family prior to and after the diagnosis, which is key for the intervention process. The report states, "educators have an important supporting role in the diagnostic process, as they can observe aspects of a student's behaviour in the school setting that may not be evident to the parent or the mental health professional" (as cited in Fazari, 2015). However, in many cases, some disorders are difficult to diagnose for a number of reasons (Cefnogi Cynnar Early Support, 2013). With this in mind, the role of the educator is to tailor their teaching to the child's needs (Cefnogi Cynnar Early Support, 2013) and build a support plan with the family as they continue to access services either within or outside the centre. 
With their role as emotion socializers (Denham, Bassett, \& Miller, 2017), ECEs may foster emotional competence by modeling their own emotions and contribute to shaping children's socio-emotional competencies. As the interactions between the child and teacher occur, children are able to observe the way in which ECEs express their own emotions (Denham et al., 2017). From this, children can decode emotions exhibited by themselves and others, and appropriately regulate their own emotions. Exposure to positive affirmations from ECEs within the classroom while children are exhibiting a range of emotions and behaviours can be key in their emotion regulation process (Denham et al., 2017). In contrast, negative affirmations may cause children to regress emotionally, allowing them to react inappropriately. Given the amount of time spent within the early childhood settings, it can be assumed that children's emotional competence is related to ECEs modeling of emotions.

Within the education institution, elementary school teachers depend on board resources and experts to intervene when mental health challenges occur in children (Lee, 2010). These school educators expressed that their role is only to teach, and not to be involved in the general welfare of children. Due to their lack of training in this area, some educators in the school system noted a need to progress in mental health literacy considering the fact that mental health challenges arise more frequently within the classroom (Lee, 2010). Graham et al. indicated that: Many teachers expressed an urgency and frustration in their need for additional support, including the need for more training, school counselors, time, funding, resources, coordinated approaches between all services, parental involvement, and better processes to help with student mental health problems. Teachers highlighted that they needed training to recognize the signs and symptoms of mental health problems and that they 
were just expected to cope and find resources in the community (as cited in Lee, $2010 \mathrm{p}$. 22.

Looking at the needs of elementary school teachers from the above, a call for more training in mental health to better recognize the signs of mental health problems and support children within the classroom may be needed. But what about the needs of ECEs?

\subsection{Need for professional development}

A search of the literature using databases such as Educational Resources Information Centre (ERIC) and JSTOR, found only three studies in the published literature that address the need for professional development (Farrel \& Travers, 2005; Sims et al., 2012; Isaksson et al., 2017). These studies highlighted a need for professional development in mental health training. Research findings support the need for ECEs to be more knowledgeable about children's mental health and about risk and protective factors. Sims et al. (2012) looked at Australian educators working in 11 childcare centres, and their knowledge about supporting mental health in their classrooms. Using semi-structured interviews, the data from this study suggested that there was not strong evidence of ECEs having enough knowledge of mental health and its' risk factors. The ECEs in this study suggested that there is a need for more training in mental health to link to practice. The study found that ECEs were challenged in distinguishing between normal misbehaviours and symptoms of mental health problems.

These results not only echo the importance of studying ECE knowledge regarding supporting mental health, but also the results of a study by Farrel and Travers (2005). The researchers provided Australian ECEs with a mental health training program and evaluated it with a pre-test and post-test design. In contrast to the first study, the data demonstrated before the program, ECEs were not confident in recognizing signs of mental health difficulties and the 
factors underlying young children's mental health problems. After completing the program, the ECEs confidence level significantly increased in the previous two factors measured. Additionally, Isaksson et al. (2017) conducted an empirical study which assessed how Swedish ECEs promote mental health in their classroom. Through interviews, the authors investigated what educators knew about mental health promotion and how they use that education in their practice. According to the study, ECEs reported that the relationship with the child and family, structure and positive environments are what support children's mental health in their classrooms.

The literature demonstrates ECEs and primary school teachers may not be fully equipped with knowledge and skills to support children's mental health concerns (Lee, 2010; Kulkarni et al., 2019). Lack of training and professional development is a significant barrier to children's mental health challenges (Penney et al., 2019).

\subsection{School Readiness}

Transitions from preschool to school can be stressful for children, families and the educators. School readiness refers to more than math and language skills, it also looks at children's social-emotional skills (Zero to Three, 2016). Research suggests that social-emotional development is crucial for early school success (Zero to Three, 2016; Cho, 2019). Research also tells us that by the time children start school, a number of future school problems are already evident (Bruner, 2019). Dimensions of school readiness are dependent on children's holistic development: social, emotional, cognitive and physical development (Zero to Three, 2016; Bruner 2019). Additionally, school readiness is dependent on individual, family, school and sociocultural factors (Bruner 2019). Attributes such as poverty (Wolf, Magnuson, \& Kimbro, 2017) chronic illness (Perrin et al., 1984) untreated learning disability (Bruner, 2019) and 
parental mental illness (Lee, 2010) contribute to children's lack of success in school and their mental health challenges. There are a number of prospective consequences of children's mental health challenges, including poor academic achievement and substance abuse (Lee, 2010).

When children are identified early, they may be given the services needed to support their challenges. Early childhood programs that screen and make appropriate referrals for children's developmental concerns reduce developmental delays (Bruner, 2019), thus, preparing them for academic success. Additionally, educators in childcare who are trained in supporting children's mental health concerns can recognize the challenges children exhibit and provide them with supports. Research tells us that when children enter kindergarten, many are not prepared socially and emotionally (as cited in Penney et al., 2019). According to Walsh (2018), children are better prepared for school when they are cared for by educators with knowledge and skills in socialemotional development. Moreover, educators who teach children social-emotional learning (an approach to mental health promotion) significantly improve the children's academic successes (Kulkarni et al., 2019).

Quality early childhood programs moderate the risk factors for children's mental health challenges. ECE programs play a significant role in moderating mental health problems due to the fact that they are one of the most frequent environments in which some children spend time (Penney et al., 2019). According to Isaacs, children engaged in ECE programs transition better to school than their peers who have no ECE experience (as cited in Penney et al., 2019). Successful transitions to school involve children's ability to "learn and engage in positive peer interactions... and is reflected in behaviors such as listening, following directions, and persisting at challenging cognitive tasks, is closely related to social and emotional competence and highly 
related to positive peer and teacher relationships in the classroom" (Walsh, 2018, p. 116). Early childhood programs are key in successfully preparing preschool children for school readiness.

\subsection{Conclusions}

The literature review provides evidence of the importance of early mental health within the context of early childhood education. To reiterate, this current study is aimed at building knowledge of: (1) how early childhood educators are supporting and promoting infant mental health in their classroom; (2) the strategies and resources ECEs are using in their classroom to promote mental health; (3) what ECEs consider as a mental health challenge, and (4) and what ECEs need to further support mental health in their classrooms. 


\section{CHAPTER 3}

\section{METHODS}

\subsection{Overview}

In this study, the research design chosen derives from a constructivist worldview.

Constructivism is best explained as a "philosophical view that says all knowledge is constructed from human experience as opposed to discovered self-evident knowledge" (Harvey, 2012, para. 1). A qualitative thematic analysis was chosen. This method was selected to explore and understand what ECEs know about promoting mental health in their classroom, as well as to describe how mental health is promoted in their classroom.

Additionally, this study uses a phenomenological approach which describes "the lived experiences of individuals about a phenomenon as described by participants" (Creswell \& Creswell, 2018, p. 13). In this study, the educators' beliefs and practices were explored using interviews to capture a range of perspectives of ECEs towards young children. It is hoped that data collected will help address the importance of mental health promotion. In this chapter, the design of the study, ethical consideration, participants and recruitment, data collection, and the data analysis method are presented.

\subsection{Participants}

Participants for this study were ten fulltime ECEs identifying as working in a preschool room. All the ECEs in the current study met the criteria of educators who have previously worked or who currently work in a preschool classroom. Due to COVID-19, many of the ECEs were not currently due to closures of childcare centres and schools. This was an exception that I had to make as there were only emergency childcare centres open for frontline workers. All participants answered every question in the interview. 


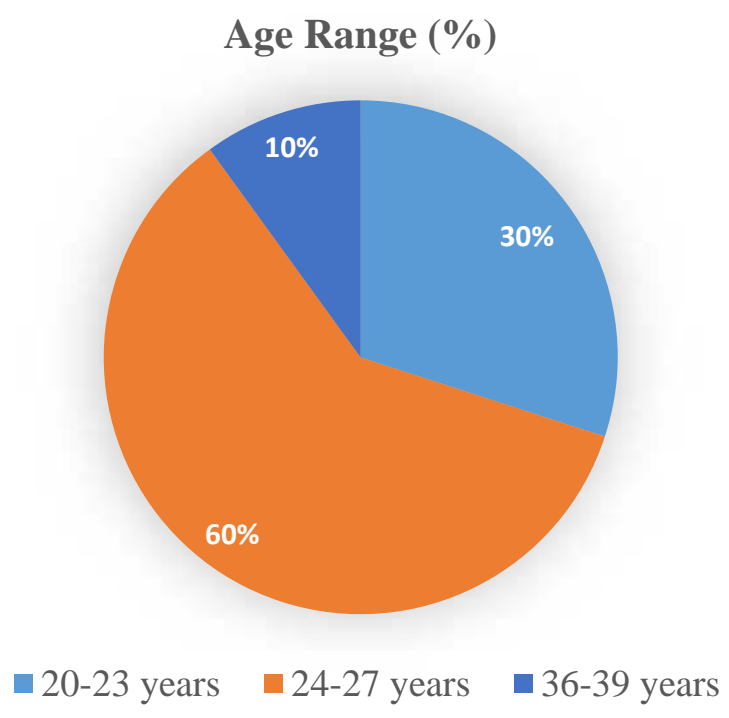

Figure 1: Age range of participants.

Participants in this study were all females, with ages ranging from 23 to 38 years old (see Figure 1). All of these ECEs identified as lead teachers in their classroom and responsible for the day to day care and education of the children in their classroom. Table 2 provides a summary of the demographic information of the participants.

Table 2.

Demographic Information

Demographic Information for Participants $(n=10) \quad$ N (\%)

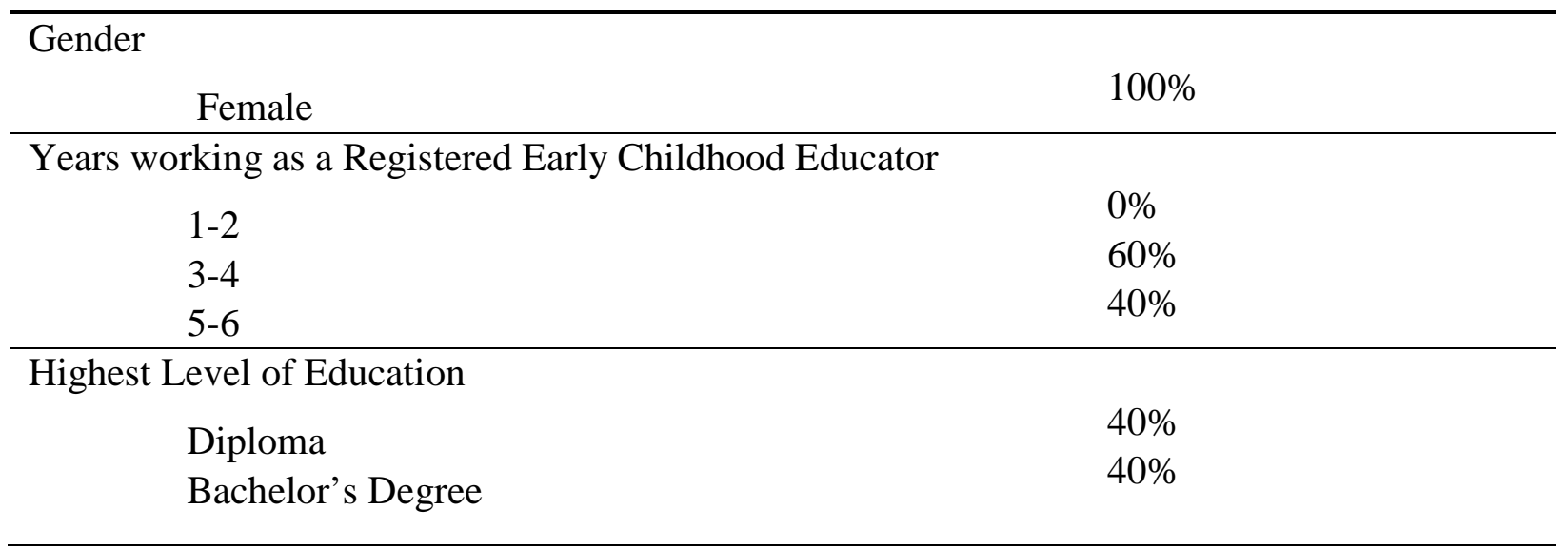




\subsection{Procedure}

Recruitment. Recruitment was conducted within the Greater Toronto Area (GTA) in Ontario, Canada. The GTA was chosen not only because of the lack of research and literature focusing on this research problem within this context, but also because Ontario is the home to one the fastest growing populations in Canada (Statistics Canada, 2019).

Due to the recent pandemic events, the recruitment process for this study involved flyers being posted to closed Facebook groups that pertain to ECEs and emails to supervisors with whom I had made connections in my professional role. The comments on the Facebook posts were disabled to ensure that the identity of participants remained private. Supervisors who were emailed were asked to only email their employees the flyer (see Appendix A) along with the prewritten email message from the researcher (see Appendix D) and to direct any questions/concerns to my research supervisor or me. The inclusion criteria for this study was that potential participants must be an early childhood educator registered with the college of ECEs, currently practicing in a childcare centre. Participants must be working fulltime in a preschool (age 3-5) room. Inclusion criteria involved potential participants of any age, gender, ethnic and racial background, educational level. Educators who just started their career as an ECE and those who have been in the field for a while were invited to participate in the study A link to the consent agreement was provided for potential participants to be informed of the details of study. Finally, a snowball technique was employed where participants were invited to share the recruitment flyer with other potential participants that they may know. 
Ethical Consideration. Prior to data collection, ethics approval was gained through Ryerson University's Research Ethics Board. Relevant documentation included recruitment flyers and letters, interview guide, consent forms and other supporting documents. The approval affirmed that this research followed ethical guidelines and procedures in terms of privacy and confidentiality, risks and mitigation protocols, and methodology and recruitment.

To ensure confidentiality and informed consent, a number of procedures were put in place. All recruitment materials highlighted the voluntary nature of the study. Further, the consent materials were also emailed to the participants prior to the interview which gave them a chance to review and ask questions. Once the participants electronically signed the consent form, a date was set for the interview. Participants were also informed that the consent form would be discussed before the commencement of the interview. Participants were reminded of the voluntary nature of the study, the nature of research in itself, study withdrawal procedures, confidentiality and anonymity procedures, final withdrawal date, and the dissemination of the findings. Participants were told that they would each receive a copy of the final paper. These ethical considerations were adopted to ensure that participants were fully informed of every aspect of the research study and their right to withdraw.

Semi-structured interviews. Semi-structured interviews were conducted with the 10 participants. The interviews took place via Zoom meetings which not only allowed for the participants to be in a location that was convenient to them, but it also allowed for everyone to follow social distancing protocols during the current pandemic. The interviews took approximately 30 minutes and were digitally recorded. The interview guide is provided in Appendix F. 
Confidentiality and Privacy. To ensure confidentiality participants were assigned a unique number while the transcriptions were being completed. All electronic files and any identifying information were coded based on the participants assigned number. The recordings were stored in an encrypted file, on a password-protected iPad that only the researcher had access to. The recordings were deleted once the interviews had been transcribed. Consent forms and names, as well as the link to the coding were kept in separate files. All information and data were digital and kept in separate password protected files for security.

Data Collection. The data were collected for this study through the use of semistructured interviews. The protocol included hand-written notes during the interviews and audiorecording. According to Creswell and Creswell, handwritten notes help to capture what is being said in the moment, and the language and words of participants (2018). Following the interviews, the audio-recordings were transcribed by the researcher, alongside the notes taken, and combined with original notes to capture what was missed during the notetaking.

\subsection{Data Analysis Approach}

The interviews were digitally recorded and transcribed for analysis. The data were analyzed through a systematic method of (1) reading through the transcripts to familiarize myself with the data, (2) grouping sections of the transcript into categories, (3) and then merging them into potential themes (Creswell \& Creswell, 2018). From those themes, a similar systematic approach was used to establish subthemes. Thematic analysis was used to identify patterns within the data (Walsh, 2018) that is crucial to understanding the knowledge and experiences of ECEs in promoting mental health.

The first step in familiarizing myself with the data were transcribing the audio recordings verbatim. Reading through the transcriptions a second time to edit for clarity also allowed me to 
become familiar with the data. The transcripts were then organized into a question/prompt and answer format to have all participants answers from one question under that one question. From each question, the answers given were coded and grouped into categories based on similarities. Key words and concepts were identified which led to the development of themes and subthemes. During each interview, thoughts, questions and notes where written in the margins to identify any comments that could be of importance to the findings. At the same time, emerging themes and patterns were also written down during the interview process. 


\section{CHAPTER 4}

\section{FINDINGS}

\subsection{Overview}

The purpose of the current study was to explore early childhood educator's knowledge and experiences about infant mental health and the signs of early mental health problems. Specifically, the study was aimed at building a knowledge of (1) how early childhood educators are supporting and promoting infant mental health in their classroom, (2) the strategies and resources ECEs are using in their classroom to promote mental health, (3) what ECEs consider as a mental health challenge, (4) and what ECEs need to further support mental health in their classrooms. In this chapter, the results are summarized for each research question.

\subsection{Research Question One: Supporting and promoting infant mental health in their classroom}

The first research question explored how ECEs promote and support children's mental health in their preschool classroom. To understand how these educators support and promote mental health, interview questions were developed to capture their knowledge, confidence levels, and preparedness in addressing mental health concerns in the classroom and with parents (see Table 3). The first question asked participants, "what role do you think ECEs should have in the identification of children who may have a mental health problem?" ECEs responded by highlighting the importance of their role; specific descriptions of their responses were significant, important, primary, and big roles. These descriptors were combined to form two main variables: important and other. Eight out 10 of the educators highlighted that their role in supporting and promoting mental health in their classroom was important. Two noted the 
importance of educators being observers of the classroom and connecting with the parents, as

they are not able to identify mental health concerns. Some participant remarks are:

"We can't identify them because we're not doctors. But if there are concerns or speculations about mental health it is more of a role to get in contact with the appropriate people that can support them and help them." (Participant 002)

"Notify the parents if they observe anything. They are in an observing role, because they can't diagnose so definitely if the child is having any issues, they can observe it. They help guide the parents throughout the process." (Participant 008)

"I think they should lead by example; they should be encouraging and supportive and promote good behavior in the classroom." (Participant 009)

\section{Table 3.}

\section{Semi- Structure Interview Question Guide}

Interview Questions

1. What role do you think ECEs should have in the identification of children who may have a mental health problem?

2. How confident would you be in speaking with a parent about concerns you may have about their child's mental health? Please elaborate on your response.

3. How would you know if a child might be experiencing a mental health problem?

What behaviours or other characteristics would you look for?

4. How would you know if a child has an anxiety disorder? A depressive disorder? ADHD?

5. What resources do ECEs have access to for managing a child with mental health problems?

6. What training have you had as an ECE about children's mental health problems?

7. Do you have any experiences with working with children with mental health problems?

Do you know what those problems were? 
8. Have you ever had to speak to a parent about concerns you had about their child's mental health?

9. How would you describe a child with good social-emotional wellbeing?

10. How would you describe a child with poor social-emotional wellbeing?

4.2.1 Perception in addressing mental health concerns. Another interview question asked participants about their confidence in addressing mental health concerns to parents. The responses were organized by an imposed scale developed by the researcher. The educators' reported how confident they would be in addressing mental health concerns to parents (see quotes below on pg. 28-29) and the researcher interpreted ECEs confidence from their responses on a ranging scale. Responses ranged from very confident, confident, somewhat confident, and not confident. Thirty percent of the respondents were very confident in addressing mental health concerns to parents, $50 \%$ were confident, $10 \%$ were somewhat confident, and $10 \%$ were not confident. Participants emphasised their confidence and lack thereof are based on their knowledge of and experiences with mental health and their relationship with the parent.

Confidence. Interview question \#2 asked participants about their confidence in speaking to parents about their children's mental health concern. After reporting their level of confidence, participants were asked to expand on why they felt the way they did (see Table 4). Fifty percent of participants who reported that they would feel confident addressing concerns to the parents, said so only if they had a relationship in which they felt comfortable to discuss mental health. It was reported that if the relationship is not there between parent and educator, then their confidence level would decrease.

"For the most part comfortable, but it depends on the parent. If the parent is not approachable, then I would ease into it as best as I can. If the parent is someone that I can talk to, then I can address it more confidently" (Participant 008) 
"I think that depends on their relationship you have with the parent because there are some parents who are not on board as I've mentioned so if you have a good relationship with the parents you can easily communicate any concerns that you may have." (Participant 006)

\section{Table 4}

\section{Responses expanding on confidence level}

\begin{tabular}{lc}
\hline List of Reasons described by participants & $\begin{array}{c}\% \text { of } \\
\text { respondents }\end{array}$ \\
\hline Relationship with parents or lack thereof & $50 \%$ \\
Lack of mental health knowledge & $30 \%$ \\
Some mental health knowledge and experiences & $20 \%$ \\
Child development knowledge & $20 \%$ \\
\hline
\end{tabular}

*percentage does not equal to $100 \%$ as some participants mentioned more than one reason

"On a scale of 1-10, I think it depends on how close you are with the family. You obviously have to build the relationship first. You can't just meet a family right of the bat and in a week and pick out the child saying, "I think they have this and this" and say it to the parent, that won't turn out well. I think on that scale of 1-10, it's a close 8 if I do have that relationship, if I don't then I wouldn't be confident at all." (Participant 004)

Additionally, 30\% of respondents found that ECEs did not have enough knowledge in mental health to be very confident in addressing mental health concerns to parents. Descriptors of these answers included the statement: "I don't know much about mental health". Twenty percent of responses supporting confidence levels were based on some mental health knowledge and experiences with working with children with mental health problems. Similarly, $20 \%$ of responses supporting confidence levels were based on the knowledge of child development and the rapid growth children encounter at an early age.

"Confident because I would have knowledge and I can have evidence from the ASQs to explain why I feel this way and I can provide them with resources on how to improve that or how to work on it" (Participant 003) 
"I'd be confident about speaking to parents because I guess with the knowledge I have and with their child, I think I'll be pretty confident and with the resource consultant too..." (Participant 005)

"If I notice something and the issue needs to be addressed, I won't waste time. At the early age of child development, everything happens to so fast and you cannot waste time, every minute counts. Even if you are wrong, it doesn't hurt to communicate your concerns with the parents because you are doing what's best for the child. Maybe the parents noticed something as well, so together you can reveal the problem fast. With little kids, there is no time to waste, the faster, the better." (Participant 007)

Experiences. Participants were asked if they had any experiences working with children who may have had a mental health problem. Responses indicated that $40 \%$ of the participants had no recollection of working with children with mental health problems. Ten percent indicated that they were unsure due to the fact that it might have been a difficult behaviour. Similarly, $60 \%$ noted that they have had experience with working with children with mental health problems. However, $20 \%$ noted that it might have been a difficult behaviour. Additionally, $40 \%$ were knowledgeable about the mental health problem: anxiety, depression, autism, and attention deficit hyperactivity disorder (ADHD).

4.2.2 Practice in Mental Health in Classroom. A follow up interview question asked participants how mental health is supported in their classroom. A range of responses highlighted the importance of checking in with children throughout the day. Responses were coded based on how many times they were mentioned. Other responses included: diversity of family (discussions and representation in the classroom); comfort zone (reading corner, quiet area); involving children in decision making; immediately responding to children's feelings; modeling appropriate classroom behaviour; connecting with parents; talking to children about feelings; and yoga and breathing exercises. 


\subsection{Research Question Two: Strategies and Resources}

The data presented in Section 4.2.1 and Section 4.2.2 also contribute to the strategies that ECEs reported using in the classroom. From Section 4.2.1, this includes building relationships with the family. As mentioned previously, almost $50 \%$ of the responses indicated the importance of having the relationship with parents to address mental health concerns. If the relationship is not present, then educators would not feel confident to address these issues. This was also echoed when the educators were asked about the strategies and resources that they use in their classrooms.

"If we have any concerns, we collaborate with the family to create goals and make sure the child receives supports at home and at daycare." (Participant 004)

"We share the strategies with the parents as well so that we are both on the same page" (Participant 010)

Additionally, from Section 4.2.2, educators were asked about their practice in supporting and promoting mental in the classroom. The responses given highlighted their practice in the classroom, which speaks to their classroom strategies. One educator was able to describe and explain her mental health promotion practice in depth, which captured a majority of the listed responses in Section 4.2.2.

"Most of it is just conversations with the children and parents. We talk about physical exercise, how to stay healthy and active. We talk to them about feelings, how to discuss with an adult about problems that they may have. We also involve the children in decisions around the curriculum so we ask for their input on their interests and what they would like in the classroom. We have a quiet area that the children have that they can go to if they feel overwhelmed. We do morning checkups with the children so when they come in they can tell us where they're at emotionally if they feel happy or sad or angry and then we work with them throughout the day to remove them from the zone that they're in if it's not a good one. And we do check in throughout the day to see where they're at as well. We talk about feelings often in the classroom and we make sure that children are aware of other children's feelings and even our feelings as well because we play a big part in how children regulate their emotions. We have to model our own behaviors and emotions so that children can see how to do it themselves. Sometimes we 
do breathing exercises and yoga just so that children can just figure out how to calm their bodies." (Participant 007)

4.3.1 Documentation and Screening Tools. In addition to the previous strategies listed, ECEs also noted the importance of using documentation and screening tools to gather information about the child and their development. Some of the educators noted that these tools are a requirement in their childcare centre and are updated every couple of months to keep track of the children's development. One educator noted that if she did have a concern for a child in her classroom, she would use a screening tool to help narrow down her concerns and see where the child may need help.

"We also use the Brigance [a developmental screening tool] to document the children's development. Every child gets one when they start and then as they move up their new teacher gets it and continues documenting their development. And once they graduate from the centre and move to kindergarten, the parents get their book and can reflect on their development. The love it because they can see how much their child has grown. So, if I have concerns, I can use that like a reference to back up my concerns and see where the problem is." (Participant 010)

The educators referenced the use of various documentation and screening tools as their strategies in promoting and supporting mental health. Some mentioned by the educators include hand-written notes, observations in the classroom, Brigance Inventory of Early Development: Early Childhood Screen, Ages and Stages Questionnaires (ASQ): ASQ-3 and ASQ-SocialEmotional Second Edition (ASQ-SE2), and the Early Learning for Every Child Today (ELECT) document. The data were coded to identify discussions around documentation and screening tools. Question five asked participants about access to resources in the classroom to support children's mental health; $40 \%$ of respondents mentioned the use of documentation and screening tools.

4.3.2 External Resources. In addition to the documentation and screening tools, ECEs also noted the use of external resources. Ninety percent of the respondents highlighted the use of 
resource consultants. Of all the participants, $30 \%$ relied only on the resource consultants to intervene and provide classroom management strategies. Ten percent of the respondents highlighted the use of early interventionists. Additionally, participants also reported access to various workshops and the use of community resources. It was reported that educators sometimes make recommendations to families who may not know where to go or if the childcare centre in unable to provide that specific type of support. Further, community resources also included connecting families to EarlyOn Centres to connect those practitioners with the family. After connecting the family with these community resources, the educators connect back with the family to incorporate strategies in the classroom that were suggested by community resource practitioners. Further, participants also described the role of supervisors. It was reported that supervisors also play a role in connecting both the early childhood educator and the family to external resources. Participants also reported that supervisors intervene if parents are reluctant to hear the educators concerns that they may have about their child. Lastly, one participant noted the use of Toronto District School Board's (TDSB) autism disability program as resource available to her childcare centre.

"We have their resource consultant from the city. Our boss sometimes gives us a few resources. TDSB is a part of our daycare as well so they have an autism disability crew; they are available to us as well." (Participant 005)

\subsection{Research Question Three: Concept of mental health}

4.4.1 Behaviour Type. Five questions were developed to investigate how ECEs identified children's positive and negative mental health. First, educators were asked how they would know if a child is experiencing a mental health problem. Eighty percent of respondents mentioned behaviours and 20\% highlighted developmental milestones (see Table 5). Participants who stated behaviours were asked to expand and describe what behaviours or characteristics that 
identify children as having mental health challenges. Additionally, participants who highlighted developmental milestones were asked to also elaborate on their responses. Table 5 captures the behaviour type and the frequency each behaviour was mentioned.

\section{Table 5}

\section{Behaviour Type and frequency of behaviours reported}

\begin{tabular}{lc}
\hline Behaviour Type & $\begin{array}{c}\text { Frequency (\# of times } \\
\text { reported) }\end{array}$ \\
\hline Aggression & 7 \\
Alone time, distant & 7 \\
Poor listening skills & 3 \\
Unable to follow routine & 3 \\
Poor emotional regulation & 4 \\
Tantrums for long period of time & 1 \\
Sad all the time & 3 \\
Not eating & 2 \\
Anger & 1 \\
Frustration & 2 \\
Repeating actions over and over & 1 \\
again & \\
$\quad$ No eye contact & 2 \\
Not getting along with other & 2 \\
children
\end{tabular}

*number of times behaviour type were reported by respondents

The most frequent behaviours reported by respondents were aggression and alone time, both being reported 7 times each. This means that $70 \%$ of the educators in this study describes children demonstrating aggressive behaviour and engaging in alone time/distant as a major 
concern for mental health challenges. Furthermore, educators who highlighted failure to meet

developmental milestones relied on their knowledge of child development and screening tools.

"If they're not meeting their developmental milestones. I would look at the relationship that they have with their caregivers or mothers, I would look at their language look at their cognitive development to see if they are hitting all their milestones if they score low on the social emotional ASQ." (Participant 003)

"It will affect all domains: social, emotional, language, cognitive. They're all interrelated. For mental health, we'll look at behaviours so if the child shows some concerning behaviours, it means that something is wrong and it will affect everything; how he interacts with other children, affect their social development, their emotional development, how they regulate their emotions and how they feel: happy, angry, frustration, you might see a lot of negative emotions. It might also affect cognitive development; something is bothering him so he may not function $100 \%$ academically or cognitively. Language wise, not being able to communicate. We have developmental milestones, we screen for issues, so it'll show us things that are not going well for the child." (Participant 007)

4.4.2 Descriptors of mental health problems. Participants were asked to describe a child who is experiencing three specific mental health problems: depressive disorder, anxiety disorder, and ADHD. Although the role of the educator is not to diagnose, participants were told that these mental health problems are the most commonly found mental health challenges in preschool. Participants were also told that these questions were asked in order to get a sense of their knowledge surrounding diagnosed mental health problems. Of all three disorders, all the educators were able to speak about a child with ADHD. Two participants were unsure about depressive disorder, and three were unsure about anxiety disorder. Additionally, participants who had previous experiences working with children with these mental health problems were able to speak to those specific disorders. This suggests that the ECEs may not know what the disorders are. The disorder receiving the least reported descriptors was anxiety disorder. Table 6 captures the various descriptors of each disorder. 


\section{Table 6}

\section{Descriptors of Mental Health Disorders}

\begin{tabular}{lc}
\hline Disorder Type & Descriptors \\
\hline Depressive & Alone, not engaged, not focused, seem sad, easily \\
inxitated, not sleeping, no interactions with others & Problems with attachment relationship, crying often, \\
Anxiety & $\begin{array}{c}\text { overall anxious/eager, not following the rules, not focused, } \\
\text { difficulty with tasks and schedules, afraid, overwhelmed }\end{array}$ \\
ADHD & Hyper (always moving, can't sit on carpet for too \\
& long, can't stand in line, bouncing off the walls), very active, \\
& not focusing on activity for long periods of times, need one- \\
on-ones
\end{tabular}

*descriptors were based on frequency of each response

Participants were given a scenario of a child (Jessie) who may be at risk for developing a depressive disorder (Appendix F). The scenario involved descriptions taken from the Diagnostic Classification of Mental Health and Developmental Disorders of Infancy and Early Childhood (DC: 0-5). To reiterate, some of the diagnostic criteria include:

"depressed mood or irritability across activities, more days than not for at least two weeks, as indicated by either the child's direct expression, (e.g., "I'm sad") or observations made by others (e.g., the young child appears sad or is tearful, affect is flat, or the young child has frequent tantrums). Markedly diminished pleasure or interest at all, or almost all, activities, such as imitation of play and interaction with caregivers - across activities. Significant change in appetite, insomnia or hypersomnia, fatigue or loss of energy" (Zero to Three, 2005, p. 66).

Participants were asked if they had any concerns for Jessie and what they would do about those concerns. Eighty percent of participants reported that they indeed had concerns for Jessie, while 
$20 \%$ indicated that they do and do not have concerns for Jessie. The $80 \%$ who reported concerns for Jessie highlighted the behaviours combined together is not normal. To address the concerns they have, all the educators mentioned connecting with the parents to determine Jessie's behaviours at home and how-to better support Jessie in the classroom. These actions involve asking parents about Jessie's interests regarding activities and foods as there may be cultural impact of the classroom on his behaviour. One educator said that there may be problems at home, so it is important to connect with the parents to figure out what is going on and why it is going on. The educators also suggested that Jessie may use a nap time stuffed animal at home so incorporating that into the classroom may help Jessie sleep. Educators also mentioned that they would discuss with Jessie what his interests are and implement that in the classroom.

Additionally, educators highlighted connecting with their supervisors to inform them about what is happening, and to inquire about additional resources and strategies. One participant was able to identify that Jessie might be experiencing depressive disorder. She connected the behaviours of Jessie to a child she had observed and who had later been diagnosed with depression.

"I think Jessie might be depressed; she exhibits similar behaviours as the one girl I experienced with depression." (Participant 005)

(Interviewer: How would you know if a child has a depressive disorder?) For depressive disorder, a child not being engaged in any activities in the classroom, being really sad, wanting to be left alone, I guess not talking a lot. I had a child last year who wasn't feeling great at all, the parents had told me that they found out he was diagnosed with depression a few weeks after I had mentioned it to them. She wouldn't engage in any activities anymore; she would sit at the back of the classroom drawing on her own and whenever her friends would ask her to come play, she wouldn't. She must be very sad. She was just very out of it. I guess based off that, I would look for behaviours and characteristics that she displayed.

The $20 \%$ of respondents who had little concern for Jessie claimed that Jessie's symptoms could be related to developmental changes. One participant stated that: 
"A lot of time their food habits change when they grow, so they're either eating less or more. So, if they're not eating it's not a concern because when they are ready, they will eat. We'll just tell the parents that they didn't eat and coordinate with them to see what they like to eat so it's not a flag for me. At nap time we have children who don't sleep so it's not a concern for me either. Some children don't like to play with others, and they can't play well with others so that's not really a concern for me."

4.4.3 Social-emotional well-being. In addition to describing mental health challenges and description of children experiencing mental health disorders, the researcher also wanted to investigate how educators define positive social-emotional development and well-being. The educators were asked to describe a child with good social-emotional well-being and poor socialemotional well-being. To determine the concept of good and poor social-emotional well-being, the researcher developed a criterion based on the ASQ-SE2 (see Table 7). Each answer given by the participants was analyzed see where it fit the criteria elements (i.e. "If I ask them to calm their bodies they can sit and read by themselves" is equivalent to \#3 and \#8). For interview question 9, participants were scored out of 17 points. For question 10, participants were scored out of 12 points.

\section{Table 7}

\section{Social-emotional Well-being Criterion (Squires \& Bricker (2009).}

Good Social-emotional Well-being

1. A child who looks at you when you're talking to him.

2. Child talks and/or plays with adults they know well.

3. When upset, can calm down within 15 minutes.

4. Child like to be hugged or cuddled.
Poor Social-emotional Well-being

1. Clings to you more than you expect

2. Seems too friendly with strangers

3. Cry, scream, or have tantrums for long periods of time

4. Have eating problems, such as stuffing foods, vomiting, eating nonfood items

5. Seem more active than other children his age 


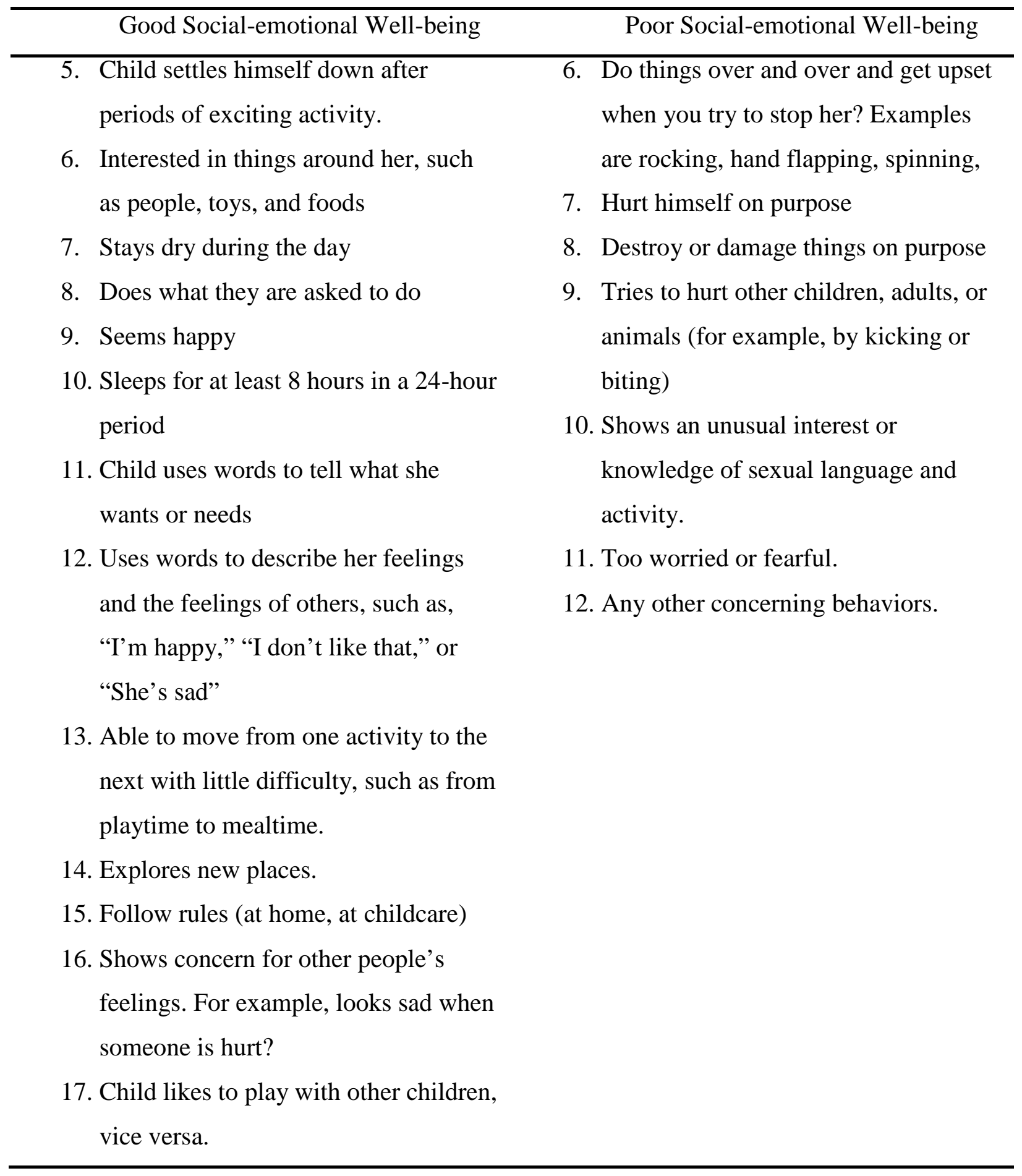

The results are summarized in Table 8 . In general, the educators demonstrated some knowledge of children's social-emotional well-being. The average number of items reported across the ten respondents was 9 out 17 for good social-emotional well-being and 7.4 items out 
of 12 for poor social-emotional well-being. It was found that educators did better at describing the features of poor social-emotional well-being than they did at describing the features of good social-emotional well-being.

Table 8.

Criterion Scores of Social-emotional Well-being

\begin{tabular}{|c|c|c|c|c|c|c|c|c|c|c|c|}
\hline Participant & P.001 & P.002 & P.003 & P.004 & P.005 & P.006 & P.007 & P.008 & P.009 & P.010 & Mean \\
\hline $\begin{array}{l}\text { Good } \\
\text { Social- } \\
\text { Emotional } \\
\text { Score }^{\mathrm{a}}\end{array}$ & 12 & 12 & 4 & 8 & 9 & 2 & 9 & 7 & 9 & 11 & 9 \\
\hline $\begin{array}{l}\text { Poor } \\
\text { Social- } \\
\text { emotional } \\
\text { Score }^{\text {b }}\end{array}$ & 8 & 8 & 1 & 8 & 5 & Null & 9 & 7 & 10 & 8 & 7.4 \\
\hline
\end{tabular}

Note: ${ }^{a}$ Number of items identified out of $17 .{ }^{\text {b}}$ Number of items identified out of 12

\subsection{Research Question Four: Further Support Needed}

To understand what ECEs require to further support mental health in their classroom, interview questions were developed around training and supports. Interview question 6 asked participants what training they have had about children's mental health. Two categ ories emerged from their responses, concerning workshops and other trainings. Sixty percent of the respondents indicated that ECEs attended workshops to improve their knowledge. Of these participants, 20\% attended workshops about the topic of mental health. The other $80 \%$ of these participants attended workshops that discussed classroom management, managing challenging behaviours, connecting with families, and interprofessional practices. These participants indicated that they had no knowledge of infant mental health workshops.

Additionally, the remaining $40 \%$ of the participants indicated they have not completed any workshops on infant mental health and have no knowledge of infant mental health workshops being offered. It was mentioned that some childcare centres provide workshop 
opportunities for educators. However, the majority of workshops are about managing difficult behaviours. In addition to the childcare centres workshop opportunities, the educators also mention that the College of Early Childhood Educators (CECE) requires registered educators to practice continuous learning (CPL) (as discussed in Chapter 1). Educators state that they have the opportunity to develop goals and use workshops and resources to reach their goals. However, only one educator had taken mental health workshops for their CPL.

Furthermore, educators indicated a need for resources and training in mental health while in practice. Educators stated that the majority of their mental health training occurred while in school. It was highlighted that mental health is something that is not talked about. Some statements include:

"I'm sure there are workshops that I can go to, but I don't go to workshops because I don't feel, like, mental health is promoted that well; there are not many workshops on mental health.” (Participant 002)

"Most of my training in mental health was because of school. In my undergrad degree program, we did ASQ training. And in my post-graduate certificate, well it is infant mental health, so I was trained in that. But in my practice, I haven't had any training or was able to take any workshops. I don't know much about any workshops that pertains to mental health specifically" (Participant 004)

"Another thing is to give us free online training for children with mental health issues because that would help us even more. I've done a few on my own and [my workplace] has paid for some, but I feel like if a class that goes up to 2-3 weeks will be beneficial for our knowledge." (Participant 005)

"To my knowledge we've had no workshops on mental health, but in school we've had to learn about mental health challenges." (Participant 006)

"I attended a seminar that discussed mental development. However, for work, I have had no training." (Participant 007)

"In school we've had training in mental health, so there were some classes that required us to get certified in some areas like trauma and mental health. At my daycare, we have the opportunity to take workshops as well. I personally have not taken any in mental health, but I have had a co-worker who took one in supporting stressful situations 
that children encounter and suggested that we all take it; so that's one that I would be interested in the future." (Participant 010)

In general, educators expressed a need for training, workshops and resources that discuss promoting children's mental health and supporting their mental health challenges. As mental health is something that is not discussed, educators reported feelings of uncertainty in appropriately responding to children's mental health needs. 


\section{CHAPTER 5 \\ DISCUSSION}

\subsection{Overview}

The primary purpose of this study was to gain an understanding of what early childhood educators know in promoting and supporting children's mental health. Experiences in early childhood are said to shape the trajectory of children's social-emotional development throughout childhood and into adulthood (as cited in Hoffman, 2016). The aim of this study was to examine the overall mental health promotion knowledge in ECEs, and to contribute to the Canadian literature by exploring educator's beliefs, knowledge and experiences in mental health promotion and supporting mental health in their classroom. Interview questions were developed to gauge the strategies, experiences, and knowledge of some aspects of mental health promotion and ability to support children's mental health challenges in the classroom.

This chapter discusses the findings and integrates significant research that relate to the findings of this study. Two major findings will be discussed: the little mental health promotion knowledge that ECEs in this study have, and how these educator's knowledge and experience influence their practice. Further, this chapter will also present limitations and strengths of the study, as well as implications for early childhood practitioners.

\subsection{Mental Health Promotion Knowledge}

The findings established that these ECEs had little knowledge in promoting and supporting mental health in their preschool classroom. Various factors influence the educator's capacity to understand mental health promotion and their knowledge in supporting mental health. Such factors include the educators' prior education and training, experience with working with children, access to professional development workshops, and perception of mental health 
promotion. These factors will be summarized with evidence from this study and evidence from the literature.

Education and experience. The findings of this study found that pre-service educators may be somewhat prepared to promote and support mental health challenges that arise in their practice, however, not enough to be extremely confident. The educators in this study had various educational levels and reported that as a pre-service educator, they received some training in mental health. As a graduation requirement, some educators noted that they only received knowledge of children's early mental health in school. ECE programs in Canada follow national training standards (Child Care Human Resources Sector Council, 2010) which include some knowledge of mental health. Graduates from ECE programs have the educational requirement to register with the College of Early Childhood Educators (CECE). This means that ECEs should also have the skills and knowledge gained from education and training to prepare them to address the mental health needs of children. However, according to Askell-Williams and Murray-Harvey (2013), "we know very little about how successful these programs are at preparing graduates to achieve this occupational standard" (p. 203). In accordance with the literature, we still do not know much about how successful these programs are collectively, however the results from this study provides us with some knowledge. Some educators in this study reported lack of preparedness to address mental health concerns. Thus, these results may provide some insight as to how successful these programs are.

When it came to mental health knowledge within the workforce, the educators reported that they depended on their prior education and training to address mental health concerns in the classroom. One educator expressed how different the field is compared to what is being taught in schools. She continued to say that knowledge is gained from the books, and once they've entered 
the field, it is not comparable to the books. The completion of coursework can allow educators to feel prepared and promote feelings of self-efficacy (Cantrel et al., 2003). However, as feelings of preparedness to address mental health concerns were based on prior education and training, some educators in this study stated mental health is still something they are uncertain about. If preservice and in-service ECEs feel ill-equipped to appropriately respond to and address children's mental health concerns, it leaves room for children to slip through the cracks without the appropriate supports (Gilliam, 2005). In the study of Swackhamer et al. (2009), the researchers found that educators who had more content knowledge were more confident about their teaching practices. Similarly, a study looking at the knowledge of ECEs suggested that educators' mental health promotion knowledge could be improved as almost half of the participants could not report a 6 or 7 on the 7-point Likert scale of mental health knowledge (Askell-Williams \& Murray-Harvey, 2013). The results in this study demonstrated that if educators had more knowledge in infant mental health promotion, they would feel more confident to address mental health concerns.

Although the results of this study and previous studies suggest that ECEs may not feel confident in addressing mental health concerns, another study suggest that ECEs may underestimate their confidence (Jackson et al., 2013). Jackson et al. (2013) found that at the end of a classroom management training program, pre-service educators reported an increased knowledge and confidence in managing their classroom well. However, their responses through their pre-training survey indicated that they had enough knowledge of classroom management (Jackson et al., 2013). The researchers continue to say that at the end of the program, the preservice educators' responses did increase, however the need for additional training is common 
for educators to feel well-equipped (Jackson et al., 2013). In relation to this study, the educators may have underestimated their own confidence levels while self-reporting.

Findings from this study indicate that the ECE's are relying mainly on their self-reported previous training with respect to mental health in their practice. ECE's reported that there are few professional development resources dedicated to children's mental health. ECEs enter the profession with a range of skills and knowledge in child and family development. According to the Early Childhood Educator Act 2007:

The practice of early childhood education is the planning and delivery of inclusive playbased learning and care programs for children in order to promote the well-being and holistic development of children, and includes: delivery of programs to children 12 years or younger, assessment of the programs and of the progress of children in them, communication with parents or persons with legal custody of children in programs to improve the development of the children, and such other services or activities as may be prescribed by the regulations" (Government of Ontario, 2020, par. 1).

Prior to entering the field, these educators complete either a 2-year diploma in early childhood education, or a 4-year bachelor's degree in early childhood education. Depending on their level of education, ECEs will receive adequate to substantial knowledge of child development (physical, cognitive, social and emotional needs of children), pedagogy, relationships, curriculum and administration (Ontario Colleges, 2020).

Additionally, another key finding was that educators who had no experience with working with children who had mental health challenges were less confident in responding to children's mental health concerns than those who had experience. Richardson says that “educators' perspectives and practices, especially early in their professional careers, tend to be 
strongly informed by their interpretations of their own experiences as students" (as cited in Askell-Williams \& Murray-Harvey, 2013). As the majority of the educators in this current study were practicing educators for an average of 3-5 years, they might have had limited opportunities to develop the skills necessary for responding to children's mental health concerns.

Workshops. The findings from the current study established that six educators attend workshops on classroom and behaviour management, as well as conflict management with colleagues. Educators discussed having the options of taking workshops based on the requirements of the College of Early Childhood Educators (CECE) or their childcare centre. ECEs can improve their skills and practice by enrolling in professional development workshops. Although through the CECE, ECEs may be required to partake in professional development workshops, participants stated that taking mental health workshops is not required and so might only be taken if the educator is interested in that specific topic. Further, a total of eight educators also stated that they have no knowledge of mental health workshops, and that childcare centres do not require ECEs to take workshops. Thus, findings of this study as well as others suggest that childcare centres should provide their staff with opportunities for professional development and on mental health promotion (Kiefer, 2013; Sokal-Gutierrez et al., 2013; Zinsser et al., 2016).

One educator from this current study mentioned that she was able to improve her knowledge in mental health when she took a workshop that pertained to children's mental health. Similar findings from Kiefer's (2013) study established that at the end of the first mental health training programs, there were significant increases of the educator's knowledge of mental health promotion. Six months after the completion of the workshops, the increase continued. Relatedly, Farrell and Travers found that educators had increase confidence in identifying signs of mental health disorders after a mental health information training (2005). These results demonstrate that 
with the right training, educator's knowledge of mental health promotion can increase, and their confidence and ability to respond to children's mental health concerns can increase.

ECEs are in a position to influence the development and well-being of children.

However, the findings from this study and others found that there are few workshops/programs that educate ECEs on mental health promotion. According to Kiefer (2013) "there is also little research that evaluates the effectiveness of training professionals, such as childcare practitioners, about mental health promotion for children" (p. 247). This suggests that not only access to workshops and additional training are needed for professional development, but evaluations of these programs are crucial to ensure that they are doing what they are intended to do.

Perception of mental health promotion. Some educators in this study stated that they were unable to differentiate between mental health problems and children's normal behaviour. This appears to be consistent in the literature as the studies by Sims et al. (2012) and Kulkarni et al. (2019) found that educators are prompt to label behaviours of earlier mental health problems as a normal developmental phase. This reiterates that educators can increase their mental health literacy with additional training and access to workshops. The literature consistently states that "mental health is more than the absence of mental illness" (WHO, 2018). Children's mental health is defined by the state of their social-emotional development (Sokal-Gutierrez, The National Training Institute for Child Care Health Consultants, \& Lieberman, 2013). Mental health knowledge (also known as mental health literacy) is crucial for educators to "strengthen their awareness and respond appropriately to children with mental health challenges" (Lee, 2012). Additionally, without mental health literacy, mental health problems tend to get confused with challenging/normative behaviours. 


\subsection{Mental Health Promotion Practices}

The knowledge and experience that educators have influences their practice as an educator. The purpose of this study was to understand the knowledge of educators, as well as understand how they promote mental health in their classroom. The ECEs in this study reported a range of factors that influence how they address, promote and support mental health. Such factors include relationships and perceived centre supports.

Relationships. Educators in this current study defined themselves as having a primary and significant role in identifying children's mental health concerns as they are the ones consistently interacting with children. Sokal-Gutierrez et al. mention that "studies show that young children, especially infants and toddlers, who have a close relationship with a caregiver/teacher in their childcare program demonstrate better social and emotional skills. A close relationship with a child caregiver/teacher can also be a lifeline for children who lack a strong relationship within the family, e.g., through abuse or neglect" (2013, p. 10). The educators in this study highlighted the quality of their relationships with parents and children as important in promoting children's mental health. Research consistently reports that the best way to promote and support children's mental health is to encourage warm, secure, and responsive relationships between the caregiver child dyad (Sokal-Gutierrez et al., 2013; Clinton, Feller, \& Williams 2016). Some educators in this study described the importance of attachment relationships when it comes to children's social-emotional development. Specifically, responses highlighted both the importance of educator's role in the classroom and building relationships with the child. According to Clinton et al., "irrefutable evidence has indicated that attachment is linked to children's well-being and is fundamental for children's development" (as cited by Leon, 2020). This suggests that the quality of the attachment relationship encourages positive mental health in 
young children. The Good Childhood Report (an annual report that looks at children's wellbeing, particularly in the U.K.) has repeatedly indicated how vital the quality of relationships is to children's well-being (GCR, 2015; 2019). Relationships include those who are primary caregivers (Sokal-Gutierrez et al., 2013) and all the educators in this current study identified themselves as a primary caregiver.

When asked about how mental health is promoted in their classroom, responses surrounding relationship building with children were found. Responses highlighted the importance of checking in with children throughout the day, diversity of family (discussions and representation in the classroom); comfort zone (reading corner, quiet area); involving children in decision making; immediately responding to children's feelings; modeling appropriate classroom behaviour; connecting with parents; talking to children about feelings; and yoga and breathing exercises. This indicates that educators are knowledgeable about secure attachment relationships as a positive mental health intervention in their teaching practices. However, the research study of Kiefer (2013) demonstrated that at phase one of a mental health promotion training workshop, educators reported low quality responses when asked about collaborating with parents in situations that may be difficult. According to Kiefer (2013), "low quality responses demonstrated a vagueness in practitioners' understanding and application of mental health promotion principles... Little flexibility, reflection and problem solving were evident... Higher quality responses also implicitly conveyed that practitioners recognized their important role in promoting children's mental health and possessed a fair degree of confidence in taking this role on.” (p. 224-225). In accordance with Kiefer's (2013) phase one responses, it appears that the responses given by the educators in this current study could be identified as low to increased quality. 
Moreover, another aspect of interpersonal relationships in regard to mental health promotion is the relationship that ECEs have with parents. The educators stated that relationships with the parents/family are key in ensuring the well-being of children; however, if they do not have a relationship with the family, they are less likely to address mental health concerns to the family. One educator stated that they were never trained in having those difficult conversations with parents and it is an expectation to have those conversations. One educator also mentioned that a workshop option was connecting with; however, the researcher did not investigate this deeper. Through the responses of the educators in this study, communicating with and connecting with the parents were evident.

The findings of the current study correspond with other research findings from the literature. According to Endsley et al. (as cited in Kiefer, 2013), "there is evidence that good relationships between practitioners and parents are associated with healthy child outcomes" (p. 77). When educators are actively involved with children and their families, they build partnerships that promote mental health. In the study by Sims et al. (2012), both the managers and educators highlighted the importance of building relationships with the family as a way to promote mental health. Relatedly, Farrell and Travers (2005) also found that educators' confidence in addressing mental health concerns to parents/guardians improved after a training program.

The findings from this study and the literature consistently highlight ECEs reporting lack of training/ experience in building collaborative relationships with families. The literature highlights that "fostering children's positive social and emotional development within the centre optimally involves practitioners developing collaborative relationships with parents" (Kiefer, 2013, p. 47). We know the importance of connecting with families, but if educators lack the 
necessary skills to have difficult conversations with families, this leaves room for children to be missed. Thus, it appears that ECEs may need additional training and practice to increase their skills in interacting with families.

Perceived centre supports. Educators in this study highlighted the strategies and techniques performed within the classroom that support children's mental health. Some strategies include using documentation and screening tools, along with developing inclusive spaces within the classroom so that children can use when they are emotionally overwhelmed. The impact of the classroom environment also has bearing on children's mental health (Kiefer, 2013). Just as important as building relationships with child and families, educator's ability to promote children's social-emotional development emerges from the contexts that they are in (Zinsser et al., 2016). The environment of the classroom has direct influence on educators and can affect children's development indirectly. Specifically, “one particular contributor to teachers' perceptions of center climate is their experience of support (emotional or physical) during challenging situations, such as managing a child's problematic behavior." (Zinsser, 2016, p. 58).

A significant finding from this study highlighted the importance of centre supports. Some educators discussed relying on the supervisor to intervene when necessary with difficult parents, and to provide them with supports and resources to better support children's mental health concerns. Literature examining educators perceived centre support in relation to children's social-emotional difficulties is evident. One study found evidence that there is a connection between children's behaviour problems and educators perceived centre supports (Hoffman, 2016). Specifically, educators who perceived their centre to provide high levels of support managed children's problematic behaviours better. The researchers suggested that educators who believe that their centres are supportive, have more access to various resources (Hoffman, 2016). 
Additionally, there is some research suggesting that when educators feel that they are well supported in their childcare centre, they were more likely to enforce positive emotional competence in young children (Denham et al., 2017).

Despite the positive association with perceived centre supports and educators' ability to promote and support children's mental health, the literature also examines negative associations. Research suggests that educators who do not feel supported tend to report more feelings of dissatisfaction with their job, elevated stress levels and emotional exhaustion (Kiefer, 2013; Denham et al., 2017). ECEs continue to express their frustrations with job demands and their ability to provide children with quality care. A study looking at the labour market in 2003 found that educators working in childcare centres rated job satisfaction as significantly low (as cited in Kiefer 2013). Many reasons were cited by staff , “...poor wages and benefits, lack of leadership in pedagogy, curriculum and human resources, lack of access to training and professional development, less than desirable quality programs for children and working environments for staff and a working day marked by mainly custodial activities rather than the early childhood practices for which they were trained" (Kiefer, 2013, p. 49). Although job dissatisfaction was not investigated in the current study, some responses of the educators indicated inability to perform their role adequately due to ministry guidelines within the childcare centre. Specifically, educators discussed the lack of ability to divert their full attention to one child in a preschool room of 15-30 children. One educator noted:

“...in my room it's me and my other staff so we have like 30 children so it's difficult for me to take one out and then 29 children with one staff, it's over ratio... If the centres would hire a third staff, it would be a lot easier to support those children who need one-on-ones." (Participant 005). 
Additionally, another educator who was discussing her experience working with a child who may have had a mental health problem explained that the child in the scenario needed a lot of one-on-one support. She continued to voice that:

"We're not licensed for one-on-one and so it was hard. It took a whole staff out of the equation" (Participant 001)

These results demonstrate that there is a need for educators to be supported within the childcare centres. Supporting these educators within this organizational culture can enhance their teaching skills (Denham et al., 2013) which could lead to positive emotional development in young children. Further, current findings could serve as a call for advancement in educator training and evidence-based practice.

\subsection{Limitations}

This research is subject to several limitations. Firstly, the sample size of this study is small and was drawn from ECEs working in a childcare centre. Therefore, the findings cannot be generalized and transferred to the entire ECE population and settings. Further, the data were

based on educator self-reporting their knowledge, experiences, and perceptions. The potential of respondent bias could be a factor, as there were no additional data to corroborate the self-reports (i.e. observations, interviewing supervisors).

Further, the participants of this study were largely limited to the Greater Toronto Area due to the current research design and lack of research from this specific context. Additional research is needed in a broader Canadian context.

\subsection{Implications}

Infant mental health promotion addresses the preventative efforts that adults in the lives of children perform to encourage positive mental health and social-emotional development. Practitioners working with children need to have the skills, knowledge, and capacity to promote 
and support children's mental health challenges. Infant mental health promotion is crucial across many disciplines. Early childhood practitioners and policy makers both play a part in how children's mental health is supported and promoted in the classroom. This section will be discussing practices that can be implemented in the early childhood settings, as well policy changes to provide to programs dedicated in supporting the holistic development of children.

Practice. The findings of this study suggest that educators are knowledgeable about the importance of relationships with child and family; however, there are sometimes barriers to building relationships with parents. Thus, educators could benefit from training that relates to building collaborative relationships. Further, training for pre-service ECEs covers a wide range of content, as mentioned earlier. Generally, faculty members in ECE programs often have one or two significant areas of expertise, but do not always have expertise in ways to address mental health concerns and challenging behaviours (Walsh, 2018). University and College faculty must have greater knowledge of children's social-emotional development and challenges of children from birth to six years to prepare pre-service educators in creating positive social-emotional classroom climates.

Additionally, supervisors who ensure that their employees are able to provide positive emotional climates should allow educators to engage in various mental health promotion workshops and opportunities. Many educators in this study indicated a need for further training in mental health promotion. The findings suggest that educators could improve their knowledge in supporting and promoting mental health within the classroom. Additionally, the literature demonstrates that training programs that enhance educators' mental health promotional knowledge and practices are effective (Kiefer, 2013). 
Policy. In regard to educational standing, ECEs can obtain a diploma or degree in early childhood education, but there is no distinction between the duties of these two levels of education. The findings established that regardless of the educational background, ECEs still did not know much about mental health promotion. A re-evaluation of ECE program curriculum in regard to ECE ability to promote and support mental health concerns may improve ECE knowledge and skills once they have entered the field. It is vital that policymakers and stakeholders review the requirements in becoming an ECE so that children are given quality care.

In addition, the evaluation of mental health training programs and workshops are needed to ensure that they are doing what they are intended to do. Further, Kiefer's (2013) findings suggested that methods of evaluating these kinds of programs should reflect targeted audiences. According to the researcher, it is not a one size fit all approach. Specifically, "increasingly guidance around development of mental health promotion has emphasized that even universal programs (i.e., addressed to the whole population) still need to be tailored to the needs of target audiences" (Kiefer, 2013, p. 240). It is recommended that attention be given to the individual, environmental, and societal aspects of those in training and the children they will work with (Kiefer, 2013).

\subsection{Future Research}

The findings from this study create a basis for further research. Research in early childhood mental health has been increasing in the past years. However, mental health promotion for the targeted group of 0-6-year old remain limited and is even more limited in the infant and toddler age group. Additionally, further research is needed to understand what ECEs know, versus what they do. Longitudinal studies that evaluate programs and observe educators' mental 
health promotion knowledge and practices is needed to explore promotional approaches with young children. The findings from this study and the existing literature explains how important it is for educators to be cognizant of their role in supporting and promoting children's mental health concerns, and how their knowledge and skills can influence their practice. Future research should examine the impact of training programs on educators' knowledge and practice, within the Canadian context.

Lastly, future research should investigate the mental health and stressors of ECEs. An additional limitation of this study was that the researcher did not further investigate early childhood educator's stress and overall job satisfaction in Canada. The Canadian literature demonstrated that educators are continuously expressing their frustrations working as an ECE. Thus, this may influence how their perform in their classroom, and how they support and promote children's mental health, especially within the Toronto context. By investigating ECEs own mental health and stressors, it could help us understand how to further support their needs

\subsection{Conclusion}

Infant mental health promotion is an important and serious task. Research in this area continuously shows the importance of mental health promotion in relation to academic successes and life-long outcomes. However, educators receive little support and training in how to teach children those life-long skills and how to address children's mental health concerns. It is essential that educators are equipped with the knowledge and skills to recognize and respond appropriately to the challenges of children. The participants in this study recognized the importance of supporting children's mental health and the findings suggest that educators have a strong desire to provide the best care possible to children. Future research is needed to take a 
closer look at how educators promote mental health as they play a pivotal role in in children's social-emotional development. 


\section{APPENDIX}

Appendix A - Recruitment Flyer 


\section{Appendix B: Consent Agreement}

\section{Ryerson University Consent to Participate in Research}

You are being invited to participate in a research study. Please read this consent form so that you understand what your participation will involve. Before you consent to participate, please ask any questions to be sure you understand what your participation will involve.

TITLE OF THE STUDY Early Childhood Educator's Knowledge and Perception of Mental Health in their Preschool Classroom

INVESTIGATORS This research study is being conducted by Asia Leon, BA, a Graduate Student in the Master's in Early Childhood Studies. The research study is supervised by Dr. David Day, from the Psychology Department at Ryerson University.

If you have any questions or concerns about the research, please feel free to contact me, Asia Leon at asia.leon@ryerson.ca or my supervisor, Dr. David Day at dday@psych.ryerson.ca, 416$979-5000 \times 7104$.

\section{PURPOSE OF THE STUDY}

The study is designed to gain an understanding of Registered Early Childhood Educators' (RECEs) knowledge and experience with infant mental health and infant mental health promotion in their preschool classrooms. The study is looking to recruit 10 RECEs who are registered with the College of Early Childhood Educators and are currently practicing as a fulltime ECE in a preschool (age 3-5) classroom. The study is a Major Research Paper in partial completion of for the Masters in Early Childhood Studies for Asia Leon.

\section{WHAT PARTICIPATION MEANS}

If you volunteer to participate in this study, you will be asked to do the following things:

- You will be asked to participate in a one-hour video-chat interview. The interview will take place at a place that is convenient to you. Video-chat platforms consist of Zoom or Skype. If you do not feel comfortable video-chatting, you can opt for a telephone interview.

- You will be asked questions to learn more about your knowledge in supporting and promoting mental health in your classroom. Some questions you will be asked include: What role do you think ECEs should have in the identification of children who may have a mental health problem? What training have you had as an ECE about children's mental health problems? 


\section{$\underline{\text { ELIGIBILITY CRITERIA }}$}

Potential participants for this study must be an early childhood educator registered with the college of ECEs, currently practicing in a childcare centre. Participants must be working fulltime in a preschool (age 3-5) room. Potential participants of any age, gender, ethnic and racial background, educational level, entry-senior levels are invited to participate in the study.

\section{POTENTIAL BENEFITS}

There may be no direct benefits to you. However, you will be given an opportunity to reflect on your past experiences as an ECE to think critically about your practices. Participants will be contributing to the research by contributing to the growing field of infant mental health.

\section{WHAT ARE THE POTENTIAL RISKS TO YOU AS A PARTICIPANT}

The potential risk to participating in this study is very low. Participants may experience some psychological distress or discomfort discussing mental health concerns about children in their classrooms. As well, the personal nature of the questions asked in the interview may have participants reflecting on unpleasant memories. In the event of discomfort or if you are beginning to feel uncomfortable, you can skip answering a question or stop participation, either temporarily or permanently. Potential participants being recruited from childcare centres may feel obligated as supervisors are sharing recruitment materials. Supervisors are asked to not directly recruit, instead they should only direct questions and concerns to the researcher. Participation in this study is completely voluntary. Lastly, potential participants should be informed that it is my duty to report suspected child abuse if it becomes known to me that a child is in need of protection.

\section{CONFIDENTIALITY}

The information you provide will be kept confidential. You will be asked NOT to include your name in your answers. Your name is on the consent form and will be kept separately from any other information gathered about you in the course of this study. Access to the information gathered throughout the study will be limited to the Principal Investigator and her supervisor. The transcribed interview will be linked to you by a number. With your consent, the interview will be audio-recorded. The master list of participants' names, identification numbers, and audio recordings will be stored separately in a locked cabinet or password-protected computer that only the principal investigator will have access to. Hard copy documents will be stored in a locked cabinet. Electronic documents, such as the transcribed interviews, will be kept on the researcher's password-protected computer. Hard copy documents will be shredded after one year of completing the study. Audio recordings of the interviews will be deleted after the interview has been transcribed. If child abuse is reported, the researcher does have an obligation to report this to Children's Aid Society (CAS). 


\section{COMPENSATION FOR INJURY}

By agreeing to participate in this research, you are not giving up or waiving any legal right in the event that you are harmed during the research.

\section{VOLUNTARY PARTICIPATION AND WITHDRAWAL}

Participation in this study is completely voluntary. You can choose whether to be in this study or not at any time. You may withdraw your consent while you are completing the interview by telling the researcher that you would like to withdraw. You also may decline to answer any specific question(s) without withdrawing from the study by leaving the question(s) blank. If you decide later that you would like to withdraw, please contact the researcher or research supervisor at the email addresses given below. If you choose to stop participating, you may also choose to not have your data included in the study. Your choice of whether or not to participate will not influence your future relations with Ryerson University or Asia Leon, and Dr. David Day involved in the research. If you choose to withdraw, all information given by you will be destroyed within 24 hours.

\section{DATA STORAGE}

Data will be collected includes consent forms, demographic information, and audio-recordings of the interviews. The consent form will be kept separately from any other information gathered about the participants in the course of this study. Access to the information gathered throughout the study will be limited to the Principal Investigator and her supervisor.

The transcribed interviews will be linked to participants by a number. With consent, the interview will be audio-recorded. The master list of participants' names, identification numbers, and audio recordings will be stored separately in a locked cabinet or password-protected computer that only the principal investigator will have access to. Hard copy documents will be stored in a locked cabinet. Electronic documents, such as the transcribed interviews, will be kept on the researcher's password-protected computer. Hard copy documents will be shredded after one year of completing the study. Audio recordings of the interviews will be deleted after the interview has been transcribed.

To transport the data, email can be a safe and secure way of transferring sensitive data. The emails will be encrypted to ensure security and privacy. The data will be kept for five years in keeping with the American Psychological Association guidelines. As well, this will allow time to review the data for the purpose of publication. After that, hard copies will be shredded, and digital files will be deleted.

Data cannot be withdrawn after June $30^{\text {th }}, 2020$ due to the time restraints on completing the major research paper.

\section{AUDIO RECORDING}


With your consent, the interviews will be recorded. You can choose to not consent to be audiorecorded by signing below that you do not want to be audio recorded. If you do choose to be audio recorded, you can consent by checking the box below stating you consent to be audio recorded. Audio recordings will only be used for the purpose of data analysis. Audio recordings will be transcribed and then deleted after transcriptions. Prior to the transcriptions, audio recordings will be kept on a separate encrypted folder on the password-protected laptop, apart from any identifying information. The transcribed data will be kept for five years in keeping with the American Psychological Association guidelines. As well, this will allow time to review the data for the purpose of publication. After that, hard copies will be shredded, and digital files will be deleted.

\section{DATA DISSEMINATION}

The data will be used for the purpose of the student researcher's major research paper (MRP). The results of the study also may be presented at scientific conferences and published in academic journals. The Ryerson Digital Repository is where student research, including MRPs are stored. You can simply google "Ryerson Digital Repository" and click the link that says: https://digital.library.ryerson.ca. If you still cannot access the Ryerson Digital Depository, a direct link can be sent to your email if you require it. All emails will be deleted upon completion of the study.

\section{QUESTIONS ABOUT THE STUDY}

This research study has been reviewed and received clearance by the Ryerson University Research Ethics Board (REB 2020-103). If you have any questions about this process or about your rights as a participant in the study, contact Ryerson's Research Ethics Board at the address below. If you have any other questions about this study or about your participation, feel free to contact myself at asia.leon@ryerson.ca or my research supervisor, Dr. David Day at dday@psych.ryerson.ca, 416-979-5000 x7104.

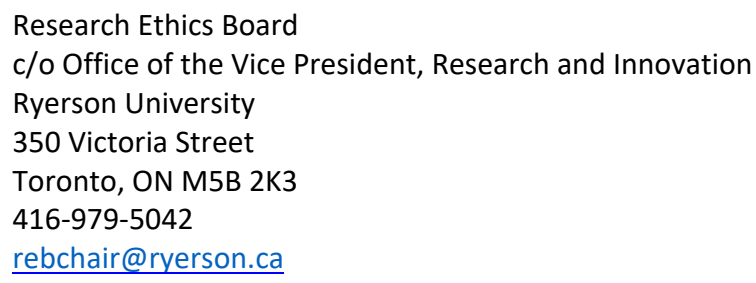

Consent: By signing this form, it means that:

- You have read the information about the study.

- You understand what the study is about and what you will be doing.

- You have been able to ask questions about the study and are OK with the answers.

- You have been given a copy of this agreement. 
- You understand that if you do not want to be part of the study, you do not need to give a reason.

- You understand that you can change your mind and withdraw your consent to participate at any time. However, data cannot be withdrawn after June $30^{\text {th }}, 2020$ due to the time restraints on completing the major research paper.

I have read and understood the information, and I agree to participate in this study. I have been given a copy of this consent form for my records.

I consent to participate

I do not consent to participate

I consent to be audio-recorded

I do not consent to be audio-recorded

Your name: (please print)

Your signature:

Date:

Your signature below indicates that you agree to being audio-recorded.

Your signature:

Date:

Interviewer's Signature

Date

\section{Regarding Interviews}

Please provide your email so that we can organize a platform for video-chatting for the sole purpose of interviews. All emails will be deleted upon completion of the research, and personal information (i.e. phone numbers, Skype I.D) will be deleted as soon as interviews are finished.

Please provide your email: 


\section{Appendix C: Facebook Post and Email}

\section{Email:}

Hello,

My name is Asia Leon, and I am a graduate student in the Master's in Early Childhood Studies program at Ryerson University. I am emailing you to invite you to participate in a research study. The title of the study is, "Early Childhood Educator's Knowledge and Perception of Mental Health in their Preschool Classroom". The study is designed to gain an understanding of Registered Early Childhood Educators' (RECEs) knowledge of and experience with infant mental health and infant mental health promotion in their preschool classrooms. The study is looking to recruit 10 RECEs who are registered with the College of Early Childhood Educators, and are currently practicing fulltime as an ECE in a preschool classroom (children aged 3-5). The study is a Major Research Paper in partial completion of for the Masters in Early Childhood Studies for Asia Leon.

Participation in this study is completely voluntary. Participants can choose whether to be in this study or not at any time. Participants may withdraw their consent while they are completing the interview by telling the researcher that they would like to withdraw. Participants also may decline to answer any specific question(s) without withdrawing from the study by leaving the question(s) blank. If participants decide later that they would like to withdraw, please contact the researcher or research supervisor at the email addresses given below. If participants choose to stop participating, they may also choose to not have their data included in the study. Participant's choice of whether or not to participate will not influence their future relations with Ryerson University or Asia Leon, and Dr. David Day involved in the research. If participants choose to withdraw, all information given by them will be destroyed within 24 hours.

This study has been reviewed and approved by the Ryerson REB (REB 2020-103).

Please take a moment to read through the recruitment flyer and the attached consent agreement form to get an understanding of the purpose of the study, what participation means, and confidentiality.

If you have any questions or concerns about the research, please feel free to contact me, Asia Leon at asia.leon@ryerson.ca or my supervisor, Dr. David Day at dday@psych.ryerson.ca, 416979-5000 x7104.

\section{Facebook:}

Hello!

I am conducting a research study takes a look at early childhood educator's knowledge in mental health promotion. The study is a Major Research Paper in partial completion of for the Masters in Early Childhood Studies for myself. If you are a fulltime registered ECE working in a preschool room with children aged 3-5, you are invited to participate! My contact information is on the flyer. Please feel free to ask me any questions or send me a private message. For the protection of your identity, please only respond privately. The comments will be disabled. 


\title{
Appendix D: Supervisor Email
}

\author{
Supervisor Email
}

Hello,

Hope you are doing well and staying safe during this challenging time! As you may know, I am a graduate student in the Master's in Early Childhood Studies program at Ryerson University. In partial completion of for the Masters in Early Childhood Studies for myself, I am conducting a research study for my Major Research Paper (MRP). I am emailing you to invite your employees to participate in a research study. The title of the study is, "Early Childhood Educator's Knowledge and Perception of Mental Health in their Preschool Classroom". The study is designed to gain an understanding of Registered Early Childhood Educators' (RECEs) knowledge of and experience with infant mental health and infant mental health promotion in their preschool classrooms. The study is looking to recruit 10 RECEs who are registered with the College of Early Childhood Educators, and are currently practicing fulltime as an ECE in a preschool classroom (children aged 3-5). Please forward this email to your employees:

$$
\text { “Hello, }
$$

My name is Asia Leon, and I am a graduate student in the Master's in Early Childhood Studies program at Ryerson University. I am emailing you to invite you to participate in a research study. The title of the study is, "Early Childhood Educator's Knowledge and Perception of

Mental Health in their Preschool Classroom". The study is designed to gain an understanding of Registered Early Childhood Educators' (RECEs) knowledge of and experience with infant mental health and infant mental health promotion in their preschool classrooms. The study is looking to recruit 10 RECEs who are registered with the College of Early Childhood Educators, and are currently practicing fulltime as an ECE in a preschool classroom (children aged 3-5). The study is a Major Research Paper in partial completion of for the Masters in Early Childhood Studies for Asia Leon.

Participation in this study is completely voluntary. Participants can choose whether to be in this study or not at any time. Participants may withdraw their consent while they are completing the interview by telling the researcher that they would like to withdraw. Participants also may decline to answer any specific question(s) without withdrawing from the study by leaving the question(s) blank. If participants decide later that they would like to withdraw, please contact the researcher or research supervisor at the email addresses given below. If participants choose to stop participating, they may also choose to not have their data included in the study. Participant's choice of whether or not to participate will not influence their future relations with Ryerson University or Asia Leon, and Dr. David Day involved in the research. If participants choose to withdraw, all information given by them will be destroyed within 24 hours.

This study has been reviewed and approved by the Ryerson REB (REB 2020-103).

Please take a moment to read through the recruitment flyer and the attached consent agreement form to get an understanding of the purpose of the study, what participation means, and confidentiality. 
If you have any questions or concerns about the research, please feel free to contact me, Asia Leon at asia.leon@ryerson.ca or my supervisor, Dr. David Day at dday@psych.ryerson.ca, 416979-5000 x7104."

Thanking you in advance for your efforts! 
Appendix E: Scenario 


\section{Appendix F: Interview Question Guide}

Ryerson

University

\section{$\underline{\text { Interview Questions }}$}

\section{Interviewer:}

"Thank you for meeting with me today. I want to tell you a little about this research before we begin:

The purpose of this interview is to learn more about early childhood educators and their knowledge in supporting and promoting mental health in their classrooms.

Some of the questions contained in this interview can be of a personal nature and pertain to sensitive topics. Your participation is voluntary. You may refuse to answer any questions or end this interview at any time."

\section{Guidelines for Semi- Structured interview:}

Demographic Information:

1. How old are you?

2. Which gender do you identify with?

Background Information:

1. What is your highest level of education?

2. How long have you worked as early childhood educator?

Knowledge and Experience:

1. What role do you think ECEs should have in the identification of children who may have a mental health problem?

2. How confident would you be in speaking with a parent about concerns you may have about their child's mental health? Please elaborate on your response.

3. How would you know if a child might be experiencing a mental health problem? 
a. What behaviours or other characteristics would you look for?

4. How would you know if a child has an anxiety disorder? A depressive disorder? ADHD?

5. What resources do ECEs have access to for managing a child with mental health problems?

6. What training have you had as an ECE about children's mental health problems?

7. Do you have any experiences with working with children with mental health problems?

a. Do you know what those problems were?

8. Have you ever had to speak to a parent about concerns you had about their child's mental health?

9. How would you describe a child with good social-emotional wellbeing?

10. How would you describe a child with poor social emotional wellbeing? 


\section{REFERENCE LIST}

Ackerman, C.E. (2020). What is self-efficacy theory in psychology? [PDF]. Retrieved from: https://positivepsychology.com/self-efficacy/

Askell-Williams, H., \& Murray-Harvey, R. (2013). Did that Professional Education about Mental Health Promotion Make Any Difference? Early Childhood Educators' Reflections upon Changes in Their Knowledge and Practices. Australian Journal of Guidance and Counselling, 23(2), 201-221. doi:10.1017/jgc.2013.19

Aviles, A. M., Anderson, T. R., \& Davila, E. R. (2006). Child and adolescent social-emotional development within the context of school. Child and Adolescent Mental Health, 11(1), 32-39.

Balter, A., Rhijn, T. M., \& Davies, A. W. (2016). The development of sexuality in childhood in early learning settings: An exploration of early childhood educators' perceptions. The Canadian Journal of Human Sexuality, 25(1), 30-40. doi:10.3138/cjhs.251-a3

Bricker, D., Davis, M. S., \&amp; Squires, J. (2004). Mental Health Screening in Young Children. Infants \& Young Children, 17(2), 129-144. doi:10.1097/00001163-20040400000005

Britto, P. R., \& Pérez-Escamilla, R. (2013). No second chances? Early critical periods in human development [Editorial]. Social Science \& Medicine, 97, 238-240.

Bruner, C. (2019). What young children and their families need for school readiness and success. Child and Family Policy Center.

Canadian Institute for Health Information. (2019). Child and youth mental health in Canada Infographic. Retrieved from: https://www.cihi.ca/en/child-and-youth-mental-health-incanada-infographic 
Cantrell, P., Young, S., \& Moore, A. (2003). Factors affecting science teaching efficacy of preservice elementary teachers. Journal of Science Teacher Education, 14(3), 177-192. Cefnogi Cynnar Early Support. (2013). Information for parents When your child has no diagnosis. Retrieved from: https://www.snapcymru.org/wpcontent/uploads/2014/09/When-your-child-has-no-diagnosis.pdf

Center on the Developing Child, (2012). Establishing a level foundation for life: Mental health begins in early childhood: Working Paper No. 6. Updated Edition. Retrieved from www.developingchild.harvard.edu.

Center on the Developing Child (2013). Early Childhood Mental Health (InBrief). Retrieved from www.developingchild.harvard.edu.

Child Care Human Resources Sector Council. (2010). ECE Post-secondary Information. Retrieved from: http://www.ccsc-cssge.ca/ece-post-secondary-information/ecec-programs

Cho, E. (2019). Sensitive periods for music training from a cognitive perspective: a review of the literature with implications for teaching practice

Cohen, J., Onunaku, N., Clothier, S., \& Poppe, J. (2005). Helping young children succeed:

Strategies to promote early childhood social and emotional development. In Research and Policy Report). Washington, DC: National Conference of State Legislatures.

Cohen, J., Oser, C., \& Quigley, K. (2012). Making it happen: Overcoming barriers to providing infant-early childhood mental health [PDF document]. Retrieved from https://www.zerotothree.org/resources/511-making- it-happen-overcoming-barriers-toproviding-infant-early-childhood-mental-health\#downloads 
College of Early Childhood Education. (2020). Notice of continuous professional learning (CPL) program requirements [PDF Document]. Retrieved from: https://www.collegeece.ca/en/Documents/CPL_Notice_ENG.pdf

Creswell, J. W., \& Creswell, J. D. (2018). Research design: Qualitative, quantitative, and mixed methods approaches. Thousand Oaks, CA: SAGE Publications.

Dougherty, L. R., Leppert, K. A., Merwin, S. M., Smith, V. C., Bufferd, S. J., \& Kushner, M. R. (2015). Advances and Directions in Preschool Mental Health Research. 14-19.

Denham, S. A., Bassett, H. H., \& Miller, S. L. (2017). Early Childhood Teachers' Socialization of Emotion: Contextual and Individual Contributors. Child \& Youth Care Forum, 46(6), 805-824. doi:10.1007/s10566-017-9409-y

Dryden-Edwards, R. (2018). Mental illness in children. Retrieved from: https://www.medicinenet.com/mental_illness_in_children/article.htm\#mental_illness_in_ children_facts

Farrell, P., \& Travers, T. (2005). A Healthy Start: Mental health promotion in early childhood settings. Australian e-Journal for the Advancement of Mental Health, 4(2)

Fazari, J. (2015). How does the Ontario education system support educators to identify and support students with mental health challenges? Toronto, ON: Ontario Institute for Studies in Education of the University of Toronto

Gartland, D., Riggs, E., Muyeen, S., Giallo, R., Afifi, T. O., MacMillan, H., Herrman, H., Bulford, E., Brown, S. J. (2019). What factors are associated with resilient outcomes in children exposed to social adversity? A systematic review. BMJ Open, 9(4), e024870. doi:10.1136/bmjopen-2018-024870 
Gellner, C. (2015). Is your child's behaviour a mental disorder or just normal development? Retrieved from: https://healthcare.utah.edu/the-scope/shows.php?shows=0_dohafiqg Giannakopoulos, G., Agapidaki, E., Dimitrakaki, C., Oikonomidou, D., Petanidou, D., Tsermidou, L., Papadopoulou, K. (2014). Early childhood educators' perceptions of preschoolers' mental health problems: A qualitative analysis. Annals of General Psychiatry, 13(1), 1-1. doi:10.1186/1744-859X-13-1

Gilliam, W. S. (2005). Prekindergarteners left behind: Expulsion rates in state prekindergartener systems. New Haven, CT: Yale University Child Study Center.

Government of Ontario. (2020). Early Childhood Educators Act, 2007, S.O. 2007, c. 7, Sched. 8. Retrieved from: https://www.ontario.ca/laws/statute/07e07

Groh, A. M., Roisman, G. I., van IJzendoorn, M. H., Bakermans-Kranenburg, M. J., \& Fearon, R. P. (2012). The significance of insecure and disorganized attachment for children's internalizing symptoms: A meta-analytic study. Child development, 83(2), 591-610.

Harmsen, R., Helms-Lorenz, M., Maulana, R., van Veen, K. (2018) The relationship between beginning teachers' stress causes, stress responses, teaching behaviour and attrition, Teachers and Teaching, 24:6, 626-643, DOI: 10.1080/13540602.2018.1465404

Harvey, L. (2012). Constructivism. Social Research Glossary, Quality Research International. Retrieved from: http://www.qualityresearchinternational.com/socialresearch/

Heckman, J.J. (2011). The economics of inequality: The value of early childhood education. Education Digest, 77(4), 4.

Hoffman, J.A. (2016). Promoting healthy social-emotional development in vulnerable young children: The importance of head start teachers and centers. Ohio State University. 
Isaksson, P., Marklund, B., \& Haraldsson, K. (2013). Promoting mental health in Swedish preschool-teacher views. Health Promotion International, 32: 53-61

Jackson, C., Simoncini, K., \& Davidson, M. (2013). Classroom profiling training: Increasing preservice teachers' confidence and knowledge of classroom management skills. The Australian Journal of Teacher Education, 38(8), 30-46. doi:10.14221/ajte.2013v38n8.2

von Klitzing, K., Döhnert, M., Kroll, M., \& Grube, M. (2015). Mental disorders in early childhood. Deutsches Ärzteblatt International, 112(21-22), 375-386.

Kiefer, H. (2013). Handle with care evaluation project: Impact of a mental health promotion training program on child care practitioners' knowledge and practices. University of Toronto.

Khodarahmi, N. (2019). Educators of young children and knowledge of trauma-informed practice. Vancouver, BC.

Kulkarni, C., Khambati, N., Sundar, P., Kelly, L., Summers, N., \& Short, K. (2019). Beyond building blocks: Investing in the lifelong mental health of Ontario's three- to six-yearolds. Ottawa, ON: Ontario Centre of Excellence for Child and Youth Mental Health

Landy, S. (2009). Pathways to competence: Encouraging healthy social and emotional development in young children (2nd ed). Baltimore, MD: Paul H. Brookes Publishing.

Lee, S. (2010). Seeking equity for mental health in public education in Ontario: A critical discourse analysis of four policy documents. Toronto, ON: Ryerson University

Leon, A. (2020). Infant mental health promotion in early childhood educator's (ECE) preschool classrooms [Research Paper]. Ryerson University.

Mukherji, P., Albon, D., \& Bowen, J. (2018). Research methods in early childhood: an introductory guide. Los Angeles: SAGE. 
National Centre for Learning Disabilities 2020. Early Identification: Normal and Atypical

Development. Retrieved from: http://www.ldonline.org/article/6047/

Ontario Colleges. (2020). What to expect from a career as an Early Childhood Educator.

Retrieved from: https://www.ontariocolleges.ca/en/programs/education-community-andsocial-services/early-childhood-education?q=\&page $=5$

Penney, S.C., Young, G.D., Butler, E., Maich, K., Philpott, D. (2019). The role of quality ECE in facilitating mental health and well-being in children. Exceptionality Education International, 29(3): 57-76.

Perrin, J., Ireys, H., Shayne, M., \& Moynihan, L. (1984). Children and Schools: The Special Issues of Chronically Ill Children. Peabody Journal of Education, 61(2), 10-15. Retrieved July 3, 2020, from www.jstor.org/stable/1491499

Poulou, M. S. (2015). Emotional and Behavioural Difficulties in Preschool. Journal of Child and Family Studies, 24(2), 225-236. https://doi.org/10.1007/s10826-013-9828-9

Shelton, T.H. (2013). Exploring preservice early childhood educators' self-efficacy beliefs and preparedness to teach students with autism spectrum disorder (ASD) in inclusive classrooms. Indiana, Pennsylvania.

Sims, M., Davis, E., Davies, B., Nicholson, J., Harrison, L., Herrman, H., Waters, E., Marshall, B., Cook, K., \& Priest, N. (2012). Mental health promotion in childcare centres: Childcare educators' understanding of child and parental mental health. Advances in Mental Health, 10(2): 138-148

Sokal-Gutierrez, K., The National Training Institute for Child Care Health Consultants, \& Lieberman, M. (2013). Mental health in the child care setting: Supporting social and emotional development training module version 3. Chapel Hill (NC): The National 
Training Institute for Child Care Health Consultants, Department of Maternal and Child Health, The University of North Carolina at Chapel Hill

Statistics Canada. (2019). Canada's population estimates: Subprovincial areas, July 1, 2018.

Retrieved from: https://www150.statcan.gc.ca/n1/en/daily-quotidien/190328/dq190328beng.pdf?st=nj2m6gd1

Squires, J., \& Bricker, D. (2009). Ages \& Stages Questionnaires®, Third Edition (ASQ®-3): A Parent-Completed Child Monitoring System. Baltimore: Paul H. Brookes Publishing Co., Inc.

Swackhamer, L., Koellner, K., Basile, C., \& Kimbrough, D. (2009). Increasing the selfefficacy of inservice teachers through content knowledge. Teacher Education Quarterly, 36(2), 63-78.

The Children's Society. (2015). The Good Childhood Report. Retrieved from: https://www.childrenssociety.org.uk/sites/default/files/TheGoodChildhoodReport2015.pd f

The Children's Society. (2019). The Good Childhood Report. Retrieved from: https://www.childrenssociety

Tugsbaatar, U. (2020). Albert Bandura: Self-efficacy for agentic positive psychology. Retrieve from: https://positivepsychology.com/bandura-self-efficacy/

Walsh, M. (2018). Early childhood mental Health consultation in early care and education: Parallel process and relationships. Widener University.

Wolf, S., Magnuson, K. A., \& Kimbro, R. T. (2017). Family poverty and neighborhood poverty: Links with children's school readiness before and after the great recession. Children and Youth Services Review, 79, 368-384. doi:10.1016/j.childyouth.2017.06.040 
World Health Organization. (2014). Mental health: a state of well-being. Retrieved from: https://www.who.int/features/factfiles/mental_health/en/

World Health Organization. (2018). Mental health: strengthening our response. Retrieved from: https://www.who.int/news-room/fact-sheets/detail/mental-health-strengthening-ourresponse

World Health Organization (2020). Child and adolescent mental health. Retrieved from: https://www.who.int/mental_health/maternal-child/child_adolescent/en/

Zero to Three. (2005). DC:0-5R: Diagnostic classification of mental health and developmental disorders of infancy and early childhood. Washington, D.C.: Zero To Three Press.

Zero to Three. (2016). Discussing infant mental health and school readiness with funders and policymakers. Retrieved from: https://www.zerotothree.org/resources/1467-discussinginfant-mental-health-and-school-readiness-with-funders-and-policymakers

Zinsser, K. M., Christensen, C. G., \& Torres, L. (2016). She's supporting them; who's supporting her? Preschool center-level social-emotional supports and teacher well-being. Journal of School Psychology, 59, 55-66. doi:10.1016/j.jsp.2016.09.001 